\title{
APOE Genotype Differentially Modulates Effects of Anti-A $\beta$, Passive Immunization in APP Transgenic Mice
}

Joanna E Pankiewicz'1,2, Jairo Baquero-Buitrago', Sandrine Sanchez' ${ }^{1}$, Jennifer Lopez-Contreras', Jungsu Kim ${ }^{4,5,6,7}$, Patrick M. Sullivan ${ }^{8,9}$, David M. Holtzman ${ }^{4,5,6}$ and Martin J. Sadowski ${ }^{1,2,3^{*}}$

\begin{abstract}
Background: $A P O E$ genotype is the foremost genetic factor modulating $\beta$-amyloid $(A \beta)$ deposition and risk of sporadic Alzheimer's disease (AD). Here we investigated how APOE genotype influences response to anti-A $\beta$ immunotherapy.

Methods: $\mathrm{APP}_{\mathrm{SW}} / \mathrm{PS}_{\mathrm{dEg}}$ (APP) transgenic mice with targeted replacement of the murine Apoe gene for human APOE alleles received 10D5 anti-A $\beta$ or TY11-15 isotype control antibodies between the ages of 12 and 15 months.

Results: Anti-A $\beta$ immunization decreased both the load of fibrillar plaques and the load of $A \beta$ immunopositive plaques in mice of all $A P O E$ backgrounds. Although the relative reduction in parenchymal $A \beta$ plaque load was comparable across all $A P O E$ genotypes, APP/ع4 mice showed the greatest reduction in the absolute A $\beta$ plaque load values, given their highest baseline. The immunization stimulated phagocytic activation of microglia, which magnitude adjusted for the post-treatment plaque load was the greatest in APP/ع4 mice implying association between the $\varepsilon 4$ allele and impaired A $\beta$ phagocytosis. Perivascular hemosiderin deposits reflecting ensued microhemorrhages were associated with vascular $A \beta$ (VAB) and ubiquitously present in control mice of all APOE genotypes, although in APP/ع3 mice their incidence was the lowest. Anti-A $\beta$ immunization significantly reduced $V A \beta$ burden but increased the number of hemosiderin deposits across all APOE genotypes with the strongest and the weakest effect in APP/ع2 and APP/ع3 mice, respectively.

Conclusions: Our studies indicate that $A P O E$ genotype differentially modulates microglia activation and $A \beta$ plaque load reduction during anti-A $\beta$ immunotherapy. The $A P O E \varepsilon 3$ allele shows strong protective effect against immunotherapy associated microhemorrhages; while, conversely, the APOE $\varepsilon 2$ allele increases risk thereof.
\end{abstract}

Keywords: Alzheimer's disease, Apolipoprotein E, $\beta$-amyloid, Brain hemorrhages, Microglia, Neurodegeneration, Therapy, Vasculopathy

\section{Background}

Accumulation of $\beta$-amyloid $(A \beta)$ in the brain is a culprit early in Alzheimer's disease (AD) pathogenesis, and triggers down-stream neurodegenerative cascades including inflammatory responses, intraneuronal neurofibrillary pathology, and synaptic and neuronal loss (reviewed in [1-3]). Susceptibility to sporadic AD is foremost modulated by $A P O E$ genotype, which also influences the load of $\mathrm{A} \beta$ parenchymal plaques and vascular $\mathrm{A} \beta(\mathrm{VA} \beta)$ deposits.

\footnotetext{
* Correspondence: sadowm01@med.nyu.edu

'Department of Neurology, New York University School of Medicine, New York, NY 10016, USA

${ }^{2}$ Department of Biochemistry and Molecular Pharmacology, New York University School of Medicine, New York, NY 10016, USA

Full list of author information is available at the end of the article
}

A single copy of the $A P O E \varepsilon 4$ allele endows a $\sim 3$ fold increase in AD risk, and $2 A P O E \& 4$ copies result in a $\sim 15$ fold risk increase, while an $A P O E \varepsilon 2$ allele halves $\mathrm{AD}$ risk relative to 2 copies of $\varepsilon 3$ (reviewed in [4]). Autopsy series and more recently positron emission tomography (PET) imaging studies of fibrillar $A \beta$ plaque load in $A D$ patients have shown $\varepsilon 4>>\varepsilon 3>\varepsilon 2$ allele gradation effect on $A \beta$ deposition [1-3]. To counteract down-stream neurodegenerative effects triggered by $A \beta$ accumulation, development of anti-A $\beta$ therapeutic strategies including anti-A $\beta$ immunotherapy have been proposed and pursued. Several anti-A $\beta$ monoclonal antibodies (mAbs) have been tested in clinical trials in AD patients and were found to significantly reduce load of fibrillar $A \beta$ as demonstrated using 
PET A $\beta$ imaging [5-8]. Whether APOE genotype also differentially modulates degree of $A \beta$ plaque load reduction in response to anti-A $\beta$ passive immunization remains unknown due to limited clinical data and because preclinical testing of anti-A $\beta$ mAbs has been exclusively conducted in $\mathrm{AD}$ transgenic $(\mathrm{Tg})$ mice models expressing wild type, murine apoE [9-12]. The main adverse effects associated with administration of certain anti- $\mathrm{A} \beta$ mAbs during clinical trials were amyloid related imaging abnormalities (ARIA) identified on magnetic resonance imaging (MRI) scans. These included vasogenic edema (ARIA-E) and cerebral microhemorrhages (ARIA-H) that in about $20 \%$ of cases are associated with clinical symptoms and signs $[13,14]$. Frequency of ARIA events and in particular ARIA-E was significantly higher among $A P O E$ \&4 allele carriers compared to non-carriers, making the APOE $\varepsilon 4$ allele a risk factor for vascular complications of anti-A $\beta$ immunotherapy $[5,8,14,15]$. In view of these considerations, we sought to re-examine the effects of passive immunization in $\mathrm{APP}_{\mathrm{SWE}} / \mathrm{PS}_{\mathrm{dE} 9} \mathrm{Tg}$ mice with targeted replacement of the murine Apoe gene for various human $A P O E$ alleles, which expression remains controlled by the native murine Apoe promoter [16, 17]. These Tg mouse lines, hereafter designated as $\mathrm{APP} / \varepsilon 2, \mathrm{APP} / \varepsilon 3$, and $\mathrm{APP} /$ $\varepsilon 4$, reflect the differential effect of $A P O E$ alleles on the load of $A \beta$ parenchymal plaques and VA $\beta$ known from $\mathrm{AD}$ patients [18]. The vaccination experiment was started in 12 months. old mice with advanced load of $A \beta$ deposits $[19,20]$, to emulate the stage of human disease in regard to $A \beta$ deposition in which anti-A $\beta$ immunotherapy is currently occurring. We used mAb 10D5 direct against $\mathrm{A} \beta_{3-7}$ epitope [10], which is known to penetrate the blood-brain-barrier (BBB) and directly binds to deposited $A \beta$ triggering microglial cells to clear $A \beta$ plaques through Fc receptor-mediated phagocytosis [9]. Our study in $A P O E$ humanized $\mathrm{APP}_{\mathrm{SWE}} / \mathrm{PS} 1_{\mathrm{dE} 9}$ mice provides evidence for differential effect of $A P O E$ alleles on response to anti$A \beta$ immunotherapy and occurrence of vascular complications associated with thereof.

\section{Methods}

All reagents and antibodies, unless stated otherwise, were purchased from Sigma-Aldrich (St. Louis, MO).

\section{Animals and antibody treatment}

All mouse care and experimental procedures were approved by Institutional Animal Care and Use Committees of the New York University School of Medicine and the Washington University School of Medicine. Generation of $\mathrm{APP} / \varepsilon 2, \mathrm{APP} / \varepsilon 3$, and $\mathrm{APP} / \varepsilon 4$ mice by cross-breeding of $A P O E \varepsilon 2, A P O E \varepsilon 3$, or $A P O E \varepsilon 4$ targeted replacement mice with $\mathrm{APP}_{\mathrm{SW}} / \mathrm{PS}_{\mathrm{dE}}$ mice and detailed genotyping procedures have been previously described [19, 20]. This study was performed using non-breeder mice of both sexes with each sex contributing approximately half to the total animal number in each experimental group. Animals separated by sex were aged in a barrier facility with a 12/12 h. light/dark cycle and ad libitum food and water access. The antibody treatment in animals of all $A P O E$ backgrounds was commenced at the age of 12 months and was carried out continuously for three months till the animals were killed at the age of 15 months. Anti-A $\beta$ 10D5 mAb or TY11-15 an isotype control IgG2a antibody $[9,10,21]$ were administered once a week $(10 \mathrm{mg} / \mathrm{kg})$ through intraperitoneal injections. The dose of 10D5 mAb used in this study was previously shown to be effective in removing $A \beta$ plaques in PDAPP AD Tg mice expressing wild type murine apoE [9, $10,22]$. Prior to each injection mice were weighted and the accurate dose of administered antibodies was quantified. Antibodies were injected diluted in $0.25 \mathrm{ml}$ of sterile phosphate buffered saline (PBS), pH 7.4 using a 29 gauge needle. Both 10D5 mAb and TY11-15 control IgG were produced, purified and provided by Janssen Alzheimer Immunotherapy. In addition to 10D5 mAb treatment and TY11-15 control groups, for each $A P O E$ genotype we analyzed a group of age-matched mice receiving no treatment or sham injections. During the treatment all animals were closely monitored for any signs of toxicity by the veterinary staff. 10D5 $\mathrm{mAb}$ and TY11-15 control IgG2a injections were well tolerated by the animals, which showed no abnormalities in the following monitored parameters: body weight, physical appearance, occurrence of unprovoked behavior, and blunted or exaggerated responses to external stimuli. At the age of 15 months all animals were killed with an overdose of sodium pentobarbital $(150 \mathrm{mg} / \mathrm{kg})$ and transcardially perfused with heparinized (1,000 units/L) $0.01 \mathrm{M}$ PBS at $\mathrm{pH} 7.4$ and temperature $37^{\circ} \mathrm{C}$.

\section{Histological processing and immunohistochemistry}

Brains were extracted from skulls and fixed by immersion in $4 \%$ paraformaldehyde in $0.1 \mathrm{M}$ phosphate buffer at $\mathrm{pH} 7.4$ for $72 \mathrm{~h}$. and then dehydrated in a mixture of $20 \%$ Dimethyl sulfoxide and 20\% glycerol in 0.01 PBS at pH 7.4 and temperature $4^{\mathrm{O}} \mathrm{C}$. Brains were cut serially along the entire rostro-caudal axis using a freezing microtome (Leica Microsystems, Wetzlar, Germany), into coronal, 40- $\mu \mathrm{m}$ thick sections, which were alternately collected into 10 series. Randomly selected series of sections were used for the following histological and immunohistochemical procedures: Thioflavin-S (Th-S) stain to visualize fibrillar component of $A \beta$ parenchymal plaques and cerebral amyloid angiopathy (CAA); anti-A $\beta$ immunohistochemistry using HJ3.4 mAb (1:250) [19, 23]; Perls' Prussian blue stain to detect perivascular ferric iron deposition [24-26]; and a combination of anti-Iba1 immunostaining (anti-Iba1 rabbit polyclonal antibody 1:1,000; Wako Chemicals USA Inc., Richmond VA) or anti-CD68 immunostaining (anti-CD68 rabbit polyclonal antibody 1:250; Abcam Inc., Cambridge, 
MA) and Th-S to characterize microglia response in association with fibrillar $A \beta$ parenchymal plaques. The intensity of HJ3.4 immunostaining was enhanced by formic acid (FA) pretreatment and the immunohistochemistry protocol was concluded using M.O.M. 3,3'-diaminobenzidine (DAB) kit (Vector Laboratories; Burlingame, $\mathrm{CA}$ ) as per manufacturer manual. The anti-CD68 and anti-Iba1 immunostaining protocol was concluded using mouse anti-rabbit IgG biotinylated antibody (1:500) followed by streptavidin conjugated Cy3 fluorochrome (1:200), as previously described [19]. Additional series from selected brains were doublestained with Perls' Prussian blue stain and HJ3.4 anti-A $\beta$ $\mathrm{mAb}$ or Th-S stain to visualize association of $\mathrm{VA} \beta$ with hemosiderin deposits. One series of sections from five randomly selected APP/ $/ \varepsilon 4$ mice treated with $10 \mathrm{D} \mathrm{mAb}$ and TY11-15 IgG controls were immunostained with 4G8 mAb $(1: 2,000)$ (Covance; Princeton, NJ) directed against A $\beta$ residues $17-24$ [20, 27]. In this case, sections were also FA pretreated to enhance $A \beta$ immunodetection and the staining procedure was concluded using M.O.M. DAB kit. This was done to verify that $10 \mathrm{D} 5 \mathrm{mAb}$ does not obscure binding of $\mathrm{HJ} 3.4 \mathrm{mAb}$ to deposited $A \beta$ since both mAbs are directed against the $\mathrm{N}$-terminus of $\mathrm{A} \beta$ while $4 \mathrm{G} 8 \mathrm{mAb}$ binds a central $\mathrm{A} \beta$ epitope.

\section{Analysis of fibrillar parenchymal plaque load and cerebral amyloid angiopathy (CAA) load}

These metrics were determined using an unbiased, wholesection quantification approach. The entire cross-sectional profile of the right hemisphere stained with Th-S, was photographed under $\times 4$ objective magnification using a high-sensitivity, cooled, monochrome DS-Qi1Mc camera attached to 80i Nikon fluorescent microscope (Nikon Corp. Tokyo, Japan). Adjacent frames were combined into a single image using the photo-stitching function of the NIS Elements imaging software (Nikon Corp. Tokyo, Japan) and analyzed with the help of NIH Image J v 1.47 image processing software package (Bethesda, MD). The crosssectional profiles of the brain cortex or the hippocampus was manually outlined on the hemispheric images and the load of all Th-S positive A $\beta$ deposits (defined as the percentage of a brain structure profile occupied by Th-S positive lesions) was automatically thresholded and filtered according to the preset algorithm to discriminate nonspecific staining. Then Th-S positive vascular deposits constituting CAA were manually eliminated from digitized images and the thresholding procedure was repeated to quantify the load of fibrillar parenchymal $A \beta$ plaques only. The CAA load was then calculated as the difference between the load of all Th-S positive $A \beta$ deposits and the load of Th-S positive parenchymal $A \beta$ plaques for a given brain section. The brain cortex was analyzed on three coronal cross-sectional profiles per brain, which were taken from levels of the anterior commissure, the rostral portion of the hippocampus (Fig 1a), and the mammillary bodies and correspond to the following stereotactic coordinates: Bregma $0 \mathrm{~mm}$, Bregma $-1.25 \mathrm{~mm}$, and Bregma $-2.8 \mathrm{~mm}$, respectively. The hippocampus was analyzed on serial coronal cross-sectional profiles through the dorsal hippocampus.

\section{Quantification of immunopositive $A \beta$ parenchymal plaque load}

The load of $A \beta$ plaques immunostained with HJ3.4 or 4G8 anti-A $\beta$ mAbs in the brain cortex was analyzed on three coronal cross-sectional profiles per brain corresponding to the aforementioned anatomical levels. The load of immunopositive $A \beta$ plaques in the hippocampus was analyzed on serial coronal cross-sectional profiles through the dorsal hippocampus. Serial microphotographs covering the entire cross-sectional profile of the brain cortex or the hippocampus were taken under $\times 20$ magnification using DS-Fi1 color camera attached to 80i Nikon microscope. Captured photographs were combined into a single image using the photo-stitching function of the NIS Elements Imaging Software, and automatically thresholded and filtered by size according to the preset algorithm to discriminate nonspecific staining and $\mathrm{A} \beta$ positive capillaries using NIH Image J v 1.47 (Bethesda, MD). The load of immunopositive parenchymal $A \beta$ plaques per brain was calculated as the average of load values obtained from all three analyzed brain sections.

\section{Assessment of cerebral capillary $A \beta$ (CCA)}

Prevalence of HJ3.4-immunoreactive capillaries was analyzed on three coronal cross-sectional profiles through the brain cortex at the aforementioned anatomical levels and on three to four subsequent coronal crosssectional profiles through the thalamus. $A \beta$ immunopositive capillaries (defined as vessels with diameter $<8 \mu \mathrm{m}[28,29])$ were manually counted at $40 \times$ objective magnification and their number was expressed as $\mathrm{n} / \mathrm{mm}^{2}$.

\section{Microglia analysis}

The analysis was performed on sections immunostained against Iba1 or CD68 antigen and counterstained with ThS. Microphotographs of the brain cortex were taken at $\times 20$ objective magnification under Tetramethylrhodamine (for Iba1/Cy3 and CD68/Cy3) and Fluorescein isothiocyanate (for Th-S) channels of 80i Nikon fluorescent microscope (Nikon Corp. Tokyo, Japan) using DS-Qi1Mc monochrome camera (Nikon Corp. Tokyo, Japan). The load of Iba1 and CD68 positive cells (defined as the percentage of a microphotograph area occupied by anti-Iba1 or anti-CD68 positive immunostaining) was automatically thresholded and filtered according to the preset algorithm to discriminate nonspecific staining using NIH Image J v 1.47 (Bethesda, $\mathrm{MD})$. To control for variable $A \beta$ parenchymal plaque load 


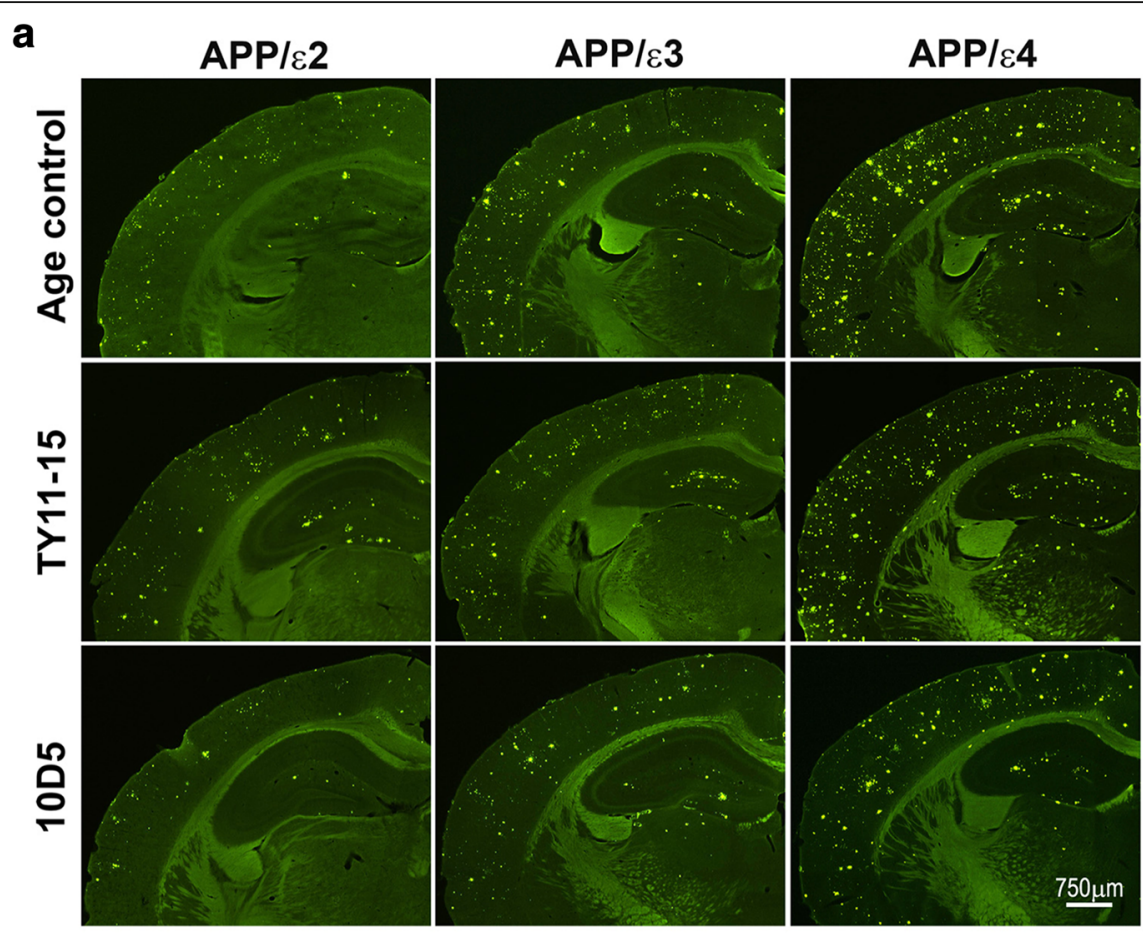

b

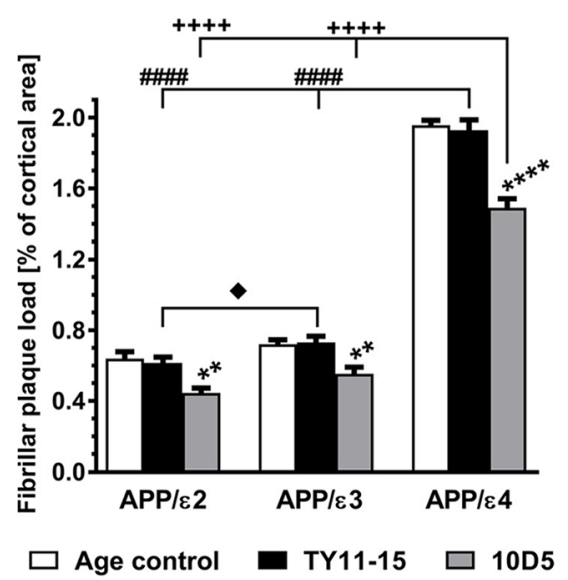

C

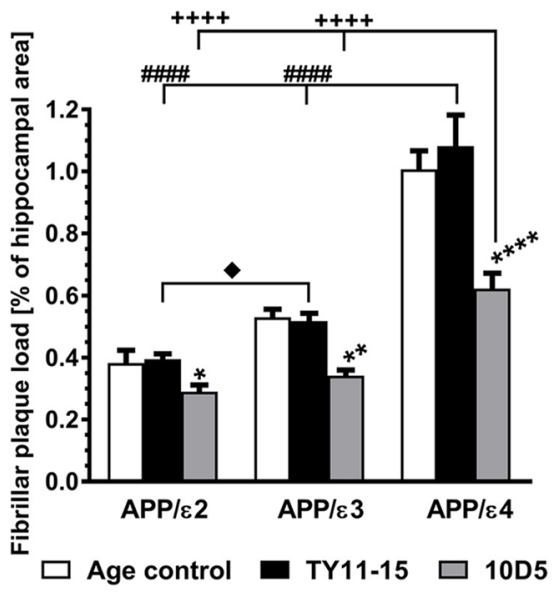

Fig. 1 Analysis of the fibrillar plaque load. APOE genotype differentially modulates fibrillar plaque load and its reduction in response to $10 D 5 \mathrm{mAb}$ treatment. a Representative microphotographs of Thioflavin-S (Th-S) stained coronal brain sections at the level of the rostral hippocampus from untreated age-matched (Age control) mice, and mice receiving an isotype control IgG2a antibody TY11-15 or 10D5 anti-A 3 mAb. Unbiased quantification of Th-S positive, fibrillar A $\beta$ plaque load in the brain cortex (b) and in the hippocampus (c). Values shown in (b) and (c) represent mean \pm SEM from 7 to 13 animals in TY11-15 and 10D5 mAb treated groups and 5 to 11 mice in Age control groups per APOE genotype. (b), and (c) $p<0.0001$ (one-way analysis of variance); ${ }^{*} p<0.05$, ${ }^{* *} p<0.01$, and ${ }^{* * *} p<0.0001$, TY11-15 control vs. 10D5 mAb treatment for matching APOE genotypes (Sidak's post hoc test). Differences between Age control and TY11-15 groups were non-significant for all matching APOE

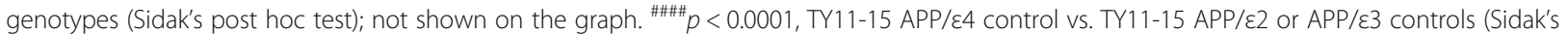

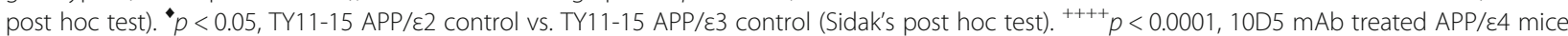

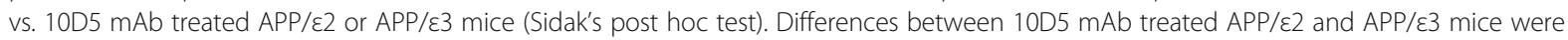
non-significant (Sidak's post hoc test); not shown on the graph. Scale bars $750 \mu \mathrm{m}$ (a)

across APOE genotypes the Iba1 load and the CD68 load was divided by the load of Th-S positive $A \beta$ parenchymal plaques determined on the same microphotograph as described above.

\section{Analysis of perivascular hemosiderin deposits}

A complete series of brain coronal cross-sections evenly spaced $400 \mu \mathrm{m}$ apart from each animal was analyzed. Such series typically includes 13-15 sections, which 
were stained with Perls' Prussian blue method without counterstain to maximize sensitivity of detection. Manual count of perivascular hemosiderin deposits in all brain structures (Additional file 2: Figure S2 A-C) was performed under $\times 20$ objective magnifications. Deposits $\geq 15 \mu \mathrm{m}$ in diameter were classified as large.

\section{Measurement of the serum cholesterol level}

At the conclusion of the experiment blood samples were collected and centrifuged to separate serum. The total serum cholesterol concentration was measured using a standard enzymatic assay based on the Cholesterol E kit (Wako Diagnostics, Richmond, VA) as previously described $[19,24]$.

\section{Statistical analysis}

Distribution of data within all data sets was analyzed with Kolmogorov-Smirnov and Shapiro-Wilk tests. Multiple data sets conforming to the normal distribution were first compared for statistical differences using one-way analysis of variance, which was then followed by Sidak's post hoc test for comparison between selected data sets. Multiple data sets, which did not conform to the normal distribution, were compared using Kruskal-Wallis one-way analysis of variance by ranks followed by Dunn's test for post hoc comparison between selected data sets. All statistical analyses were performed using GraphPad Prism v 6.05 (GraphPad Software, Inc.). All data were reported as the mean and the standard error of the mean (SEM) per APOE genotype and treatment arm for each outcome measure.

\section{Results}

\section{$A P O E$ genotype modulates reduction in parenchymal} plaque load by $A \beta$ immunotherapy

$A P O E$ targeted replacement $\mathrm{APP}_{\mathrm{SW}} / \mathrm{PS}_{\mathrm{dE}}$ mice faithfully reflect the differential effect of $A P O E$ alleles on $\mathrm{A} \beta$ brain deposition. At the age of 15 months, the load of Th-S positive, fibrillar plaques in the brain cortex of TY11-15 control $\mathrm{APP} / \varepsilon 4$ mice was 3.1 and 2.6 fold higher than that in TY11-15 control $\mathrm{APP} / \varepsilon 2$ and $\mathrm{APP} / \varepsilon 3$ mice, respectively, while in the hippocampus it was 2.7 and 2.1 fold higher, respectively $(p<0.0001)$ (Fig. 1a-c). The load of immunopositive A $\beta$ plaques in the brain cortex of TY11-15 control $\mathrm{APP} / \varepsilon 4$ mice was 1.3 and 1.6 fold higher, than that in TY11-15 control APP/ع2 and APP/ع3 mice, respectively, while in the hippocampus it was 1.5 and 1.7 fold higher, respectively $(p<0.001)$ (Fig. $2 \mathrm{a}-\mathrm{d})$. The plaque load in the brain cortex for matching $A P O E$ genotypes was higher than that in the hippocampus and the fold difference ranged from 1.4 $(\mathrm{APP} / \varepsilon 3)$ to $1.8(\mathrm{APP} / \varepsilon 4)$ for fibrillar plaque load $(p<0.01)$ and from $1.1(\mathrm{APP} / \varepsilon 4)$ to $1.3(\mathrm{APP} / \varepsilon 2)$ for immunopositive $\mathrm{A} \beta$ plaque load ( $p<0.05$ for $\mathrm{APP} / \varepsilon 2$ only). As we found no statistically significant differences in the load of fibrillar and immunopositive $A \beta$ plaques between male and female mice of the same $A P O E$ genotype, thus animals of both sexes were combined for all analyses.

10D5 mAb immunization decreased both fibrillar and immmunopositive $A \beta$ parenchymal plaque loads. The degree of reduction relative to TY11-15 controls was comparable across all three $A P O E$ genotypes. Thus, the fibrillar plaque load in the brain cortex in 10D5 mAb treated APP/ $\varepsilon 2, \mathrm{APP} / \varepsilon 3, \mathrm{APP} / \varepsilon 4$ mice was reduced by $27.7 \%(p<0.01)$, $24.4 \%(p<0.01)$, and $22.7 \%(p<0.0001)$ of the TY11-15 control mean value for matching $A P O E$ genotype (Fig. 1a, b), respectively; while the load of $A \beta$ immunopositive plaques was reduced by $43.7 \%(p<0.0001), 36.0 \%(p<0.01)$, and $44.3 \%(p<0.0001)$ (Fig. $2 \mathrm{a}, \mathrm{b})$, respectively. Similarly, the load of fibrillar plaques in the hippocampus of 10D5 $\mathrm{mAb}$ treated $\mathrm{APP} / \varepsilon 2, \mathrm{APP} / \varepsilon 3, \mathrm{APP} / \varepsilon 4$ mice was decreased by $26.7 \%(p<0.05), 34.0 \%(p<0.01)$, and $42.5 \%(p<0.0001)$ of the TY11-15 control mean value for matching $A P O E$ genotype (Fig. 1a, c), respectively; while the load of $\mathrm{A} \beta$ immunopositive plaques was lowered by $38.7 \%(p<0.001)$, $30.1 \%(p<0.05)$, and $38.3 \%(p<0.0001)$ (Fig. $2 \mathrm{c}, \mathrm{d})$, respectively. However, given significantly higher plaque load baseline in $\mathrm{APP} / \varepsilon 4$ mice, the absolute plaque load reduction effected by same dose of 10D5 mAb was incomparably higher in $\mathrm{APP} / \varepsilon 4$ mice than in other genotypes. Thus, the fibrillar plaque load in the brain cortex was reduced from $1.93 \pm 0.05 \%$ of the cortical cross-sectional area in TY11- 15 $\mathrm{APP} / \varepsilon 4$ controls to $1.49 \pm 0.06 \%$ in $10 \mathrm{D} 5 \mathrm{mAb}$ treated $\mathrm{APP} / \varepsilon 4$ mice (absolute reduction $=0.44 \%$ ), while the load of immunopositive $\mathrm{A} \beta$ plaques was reduced from $2.67 \pm$ $0.07 \%$ to $1.49 \pm 0.09 \%$ between TY11-15 and 10D5 mAb groups, respectively (absolute reduction $=1.18 \%$ ). For comparison in $\mathrm{APP} / \varepsilon 2$ and $\mathrm{APP} / \varepsilon 3$ mice the absolute reduction in the fibrillar plaque load in the brain cortex was $0.17 \%$ and $0.18 \%$, respectively; while the absolute reduction in the load of $A \beta$ immunopositive plaques was $0.89 \%$ and $0.61 \%$, respectively. Analogously, the fibrillar plaque load in the hippocampus of $\mathrm{APP} / \varepsilon 4$ mice was reduced from $1.08 \pm$ $0.10 \%$ of the hippocampal cross-sectional area in TY11-15 controls to $0.62 \pm 0.05 \%$ in $10 \mathrm{D} 5 \mathrm{mAb}$ treated mice (absolute reduction $=0.46 \%$ ), while the load of immunopositive $\mathrm{A} \beta$ plaques was reduced from $2.43 \pm 0.15 \%$ to $1.50 \pm 0.14 \%$ between TY11-15 and 10D5 mAb groups, respectively (absolute reduction $=0.93 \%)$. In $\mathrm{APP} / \varepsilon 2$ and $\mathrm{APP} / \varepsilon 3$ mice the absolute reduction in fibrillar plaque load in the hippocampus was $0.11 \%$ and $0.18 \%$, respectively; while the absolute reduction in the load of $A \beta$ immunopositive plaques was $0.62 \%$ and $0.42 \%$, respectively. Despite greater treatment effect seen in $\mathrm{APP} / \varepsilon 4$ mice, post-treatment load of both fibrillar and immunopositive $A \beta$ parenchymal plaques in $\mathrm{APP} / \varepsilon 4$ mice remained significantly higher than these in $10 \mathrm{D} 5 \mathrm{mAb}$ treated $\mathrm{APP} / \varepsilon 2$ and $\mathrm{APP} / \varepsilon 3$ mice (Fig. $1 \mathrm{~b}, \mathrm{c}$ and Fig. 2b, d).

We found no statistically significant differences between values of fibrillar plaque loads in the brain cortex and in 

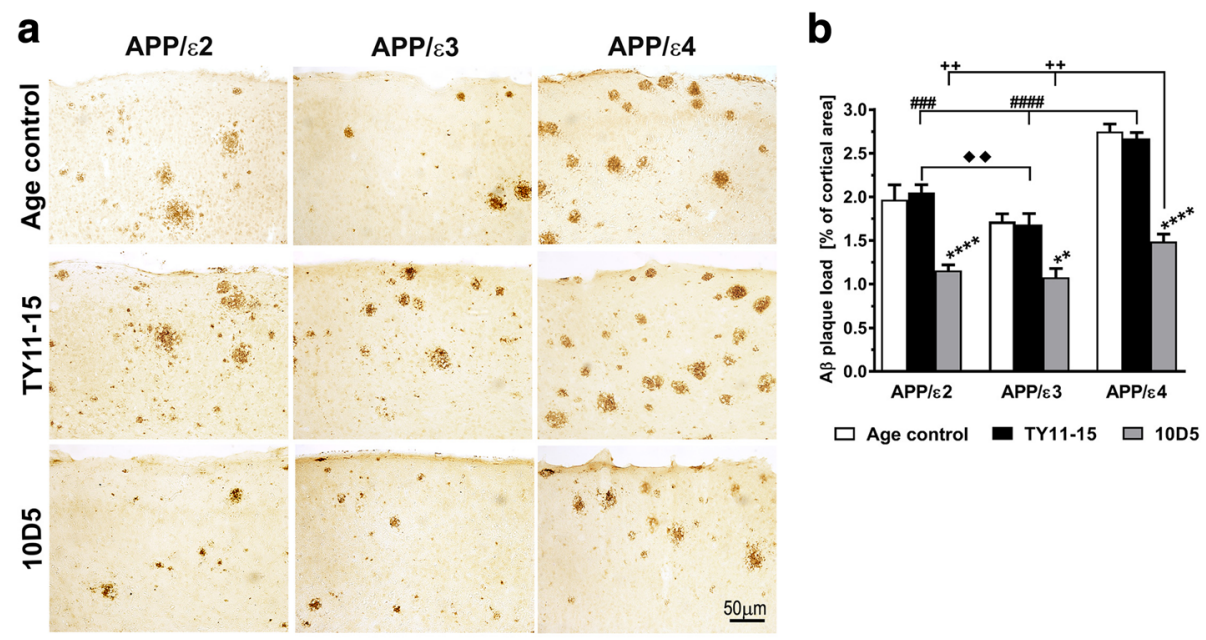

C

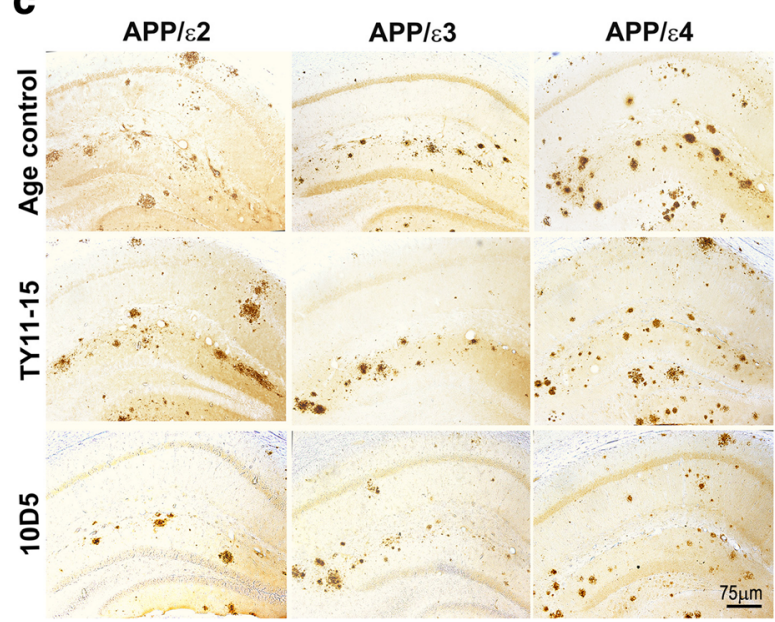

d

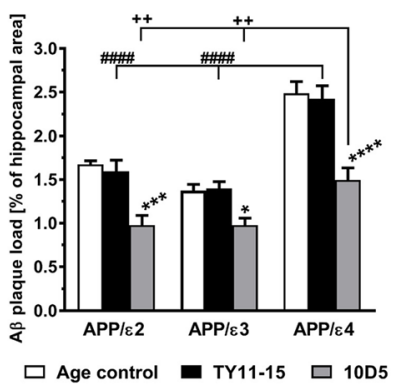

Fig. 2 Analysis of the parenchymal A plaque load. Differential effects of APOE genotype on A $\beta$ plaque load and its reduction effected by $10 D 5$ mAb treatment. Representative microphotographs of coronal brain sections through the somatosensory cortex (a) and the dorsal hippocampus (c) from untreated age-matched (Age control) mice, and mice receiving an isotype control lgG2a antibody TY11-15 or 10D5 anti-A $\mathrm{mAb}$. A 3 plaques were immunostained with an antibody against the $\mathrm{N}$-terminus of A $\beta$ following formic acid treatment of the sections. Unbiased analysis of the parenchymal $A \beta$ plaque load in the brain cortex (b), and in the hippocampus (d) revealed by anti-A $\beta$ immunostaining. Values shown in (b) and (d) represent mean \pm SEM from 8 to 12 animals in TY11-15 and 10D5 mAb treated groups and 5 to 10 mice in Age control groups per APOE genotype. (b) and (d) $p<0.0001$ (one-way analysis of variance); ${ }^{*} p<0.05,{ }^{* *} p<0.01$, and ${ }^{* * * *} p<0.0001$, TY11-15 control vs. $10 \mathrm{D} 5$ mAb treatment for matching APOE genotypes (Sidak's post hoc test). Differences between Age control and TY11-15 groups were non-significant for all matching

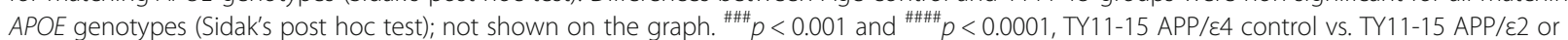

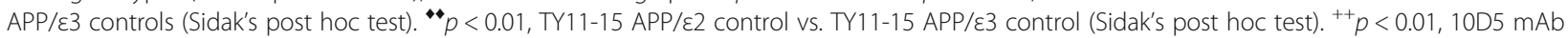

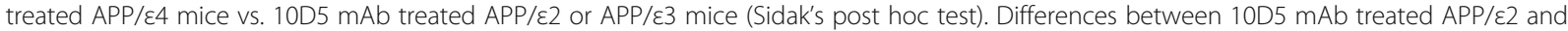
$\mathrm{APP} / \varepsilon 3$ mice were non-significant (Sidak's post hoc test); not shown on the graph. Scale bars $50 \mu \mathrm{m}(A)$ and $75 \mu \mathrm{m}(\mathbf{c})$

the hippocampus between TY11-15 isotype control IgG2a antibody treated mice and untreated age-matched mice for corresponding $A P O E$ genotypes (Fig. 1a-c). Likewise the loads of immunopositive $A \beta$ plaques in TY11-15 control and untreated age-matched mice for corresponding $A P O E$ genotypes were similar (Fig. 2a-e).

Since 10D5 mAb used for immunotherapy and HJ3.4 $\mathrm{mAb}$ used for immunohistochemistry are both directed against the $\mathrm{N}$-terminus of $\mathrm{A} \beta$ we immunostained brain section from TY11-15 control and 10D5 mAb treated $\mathrm{APP} / \varepsilon 4$ mice with $4 \mathrm{G} 8 \mathrm{mAb}$ directed against midportion of $A \beta$ [27] and compared $A \beta$ plaque load on immunostaining with both antibodies. This analysis was done to eliminate unlikely possibility that 10D5 mAb hinders the HJ3.4 epitope resulting in reduced ability to detect plaques. Average values of parenchymal $A \beta$ plaque loads revealed by 4G8 mAb immunostaining were $2.57 \% \pm 0.10 \%$ and $1.49 \% \pm 0.09$ in TY11-15 control 
and 10D5 mAb treated APP/ع4 groups; respectively; and they were not significantly different from values obtained with $\mathrm{HJ} 3.4 \mathrm{mAb}$ for the same animal groups (Additional file 1: Fig. S1 A, B).

\section{D5 mAb exerts enhanced effector response on microglia in the setting of the APOE $\varepsilon 4$ allele}

Expression of two microglia markers, Iba1 and CD68 were compared across $A P O E$ genotypes and treatment arms. Iba1 is a calcium-binding protein specifically expressed by microglia and macrophages and its expression increases with microglia activation [30]. CD68 antigen is a glycoprotein localized to the lysosomal membrane in microglia and blood derived macrophages and is up regulated in actively phagocytic cells [31]. Activated microglia expressing both markers were found in the vicinity of Th-S positive plaques in control animals of all $A P O E$ genotypes but their loads were significantly higher in APP/ $/ 4$ mice compared to APP/ع2 and APP/ $/ \varepsilon 3$ mice. The load of Iba1 positive cells in the brain cortex of TY11-15 APP/\&4 control mice was 2.9 and 2.6 fold greater than in TY11-15 $\mathrm{APP} / \varepsilon 2$ and $\mathrm{APP} / \varepsilon 3$ control mice $(p<0.0001)$ (Fig. $3 \mathrm{a}, \mathrm{b})$, respectively; while the $\mathrm{CD} 68$ load was approximately 2.9 greater $(p<0.0001) \quad$ (Fig. 3d, e). The isotype control

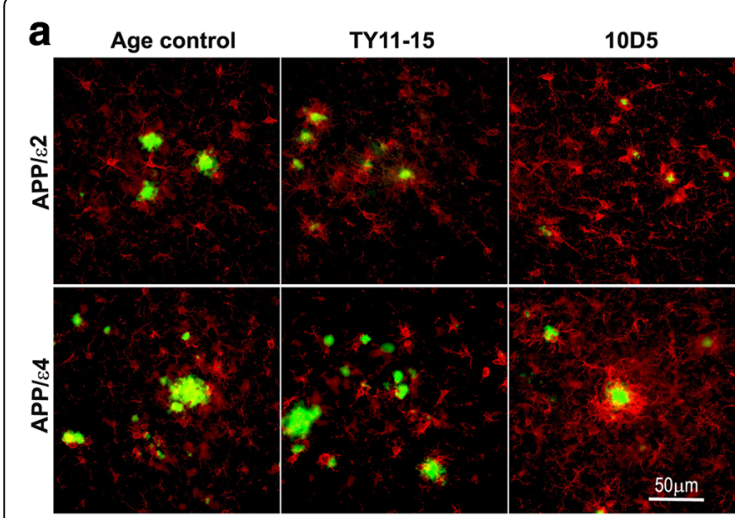

d

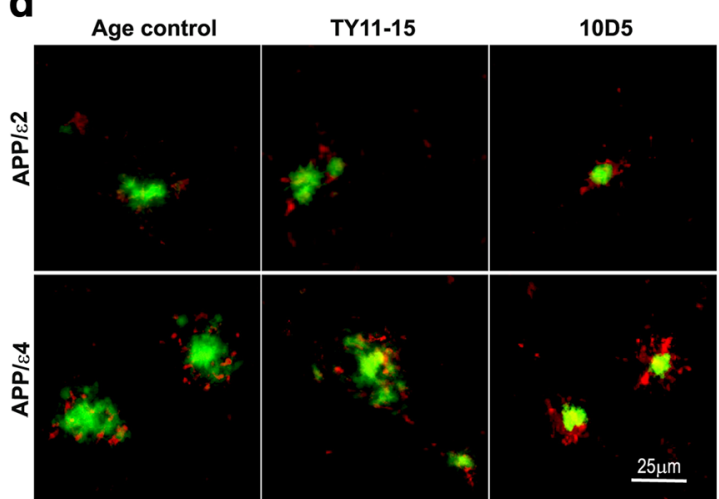

b

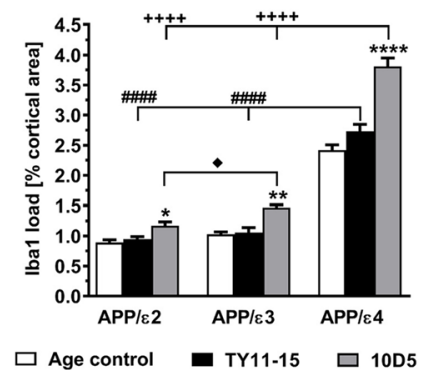

e

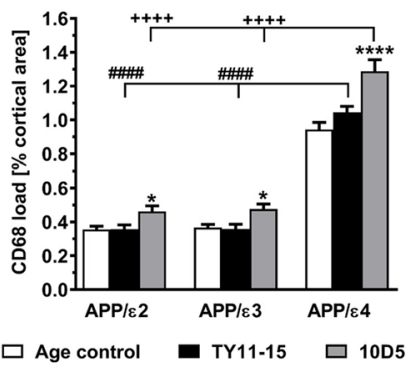

c

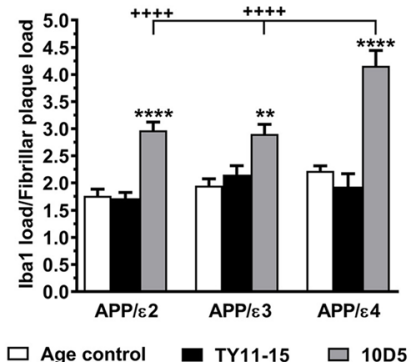

f

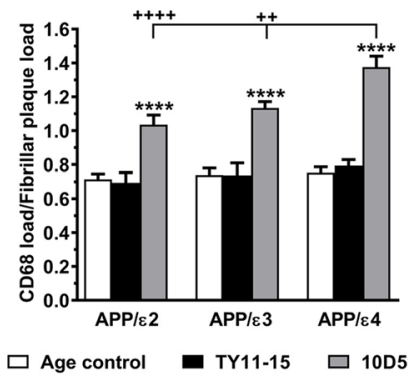

Fig. 3 Characterization of microglia response. The APOE \&4 allele is associated with enhanced microglia activation resulting from 10D5 mAb immunization compared to other APOE genotypes. a Representative microphotographs of Iba1 positive microglia in the brain cortex from untreated

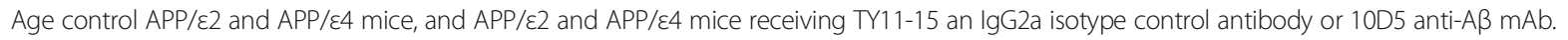
Anti-lba1 immunostaining is visualized by red color while green color reflects counterstaining of fibrillar A $\beta$ parenchymal plaques with Th-S. $\mathbf{b}$ Unbiased quantification of Iba1 positive cell load in the neocortex and (c) Iba1 load normalized to Th-S positive fibrillar plaque load across APOE genotypes and treatment arms. d Representative microphotographs of CD68 positive microglia associated with A $\beta$ parenchymal plaques from Age control, TY11-15 or 10D5 treated APP/ع2 and APP/ع4 mice. Anti-CD68 immunostaining and Th-S staining of fibrillar A $\beta$ plaques are visualized by red and green colors, respectively. e Unbiased quantification of CD68 positive cell load in the neocortex and (f) CD68 positive cell load normalized to Th-S positive parenchymal plaque load across APOE genotypes and treatment arms. Values shown in (b), (c), (e), and (f) represent mean \pm SEM from $n=11-14$ measurements/group. (b), (c), (e), and (f) $p<0.0001$ (one-way analysis of variance); ${ }^{*} p<0.05$, ${ }^{* *} p<0.01$, and ${ }^{* * * *} p<0.0001$, TY1 1-15 control vs. 10D5 $\mathrm{mAb}$ treatment for matching APOE genotype (Sidak's post hoc test). Differences between Age control and TY11-15 groups were non-significant for all

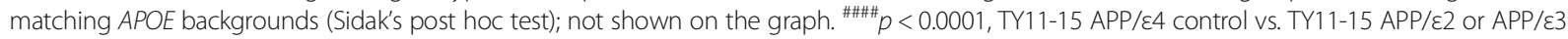

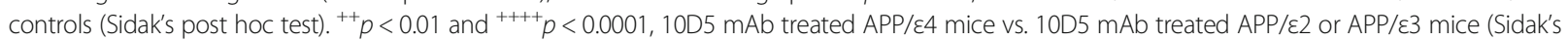

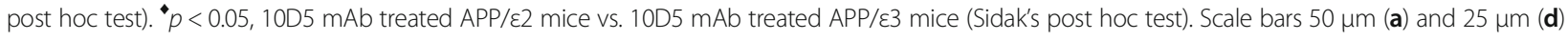


antibody TY11-15 treatment had no significant effect on Iba1 and CD68 loads as their values were similar in TY1115 control mice and untreated age-matched mice of corresponding APOE genotypes.

Passive immunization with 10D5 mAb effected significant microglia response across all $A P O E$ genotypes. The Iba1 load in 10D5 $\mathrm{mAb}$ treated $\mathrm{APP} / \varepsilon 2, \mathrm{APP} / \varepsilon 3$, and $\mathrm{APP} / \varepsilon 4$ mice was increased by $23.8 \%(p<0.05), 39.0 \%$ $(p<0.05)$, and $39.4 \%(p<0.0001)$ relative to the mean Iba1 load in TY11-15 controls of corresponding APOE genotypes, respectively (Fig. 3a, b); while the CD68 load was increased by $29.5 \%(p<0.05), 32.8 \%(p<0.05)$, and $23.3 \%(p<0.0001)$, respectively (Fig. $3 \mathrm{~d}, \mathrm{e})$.

Since the load of Iba1 and CD68 positive microglial was distinguishably the greatest in TY11-15 APP/ع4 mice, which also show the highest $\mathrm{A} \beta$ plaque load, we additionally analyzed the ratio of Iba1 and CD68 loads to the load of Th-S-positive parenchymal plaques for the same test area (Fig. 3c, f). This analysis enabled us to compare the level of microglia activation across $A P O E$ genotypes. We found no statistically significant differences in the Iba1/ Th-S ratio and in the CD68/Th-S ratio between TY11-15 control and untreated age-matched control mice across all APOE genotypes suggesting that both Iba1 load and CD68 load correlate with fibrillar plaque load. 10D5 mAb immunization effected significant increase in both the Iba1/Th-S ratio and the CD68/Th-S ratio. The magnitude of increase was comparable between $\mathrm{APP} / \varepsilon 2$ and $\mathrm{APP} / \varepsilon 3$ genotypes while in $\mathrm{APP} / \varepsilon 4$ mice it was substantially higher. In 10D5 mAb treated APP/ 44 mice the Iba1/Th-S ratio became 1.4 fold higher than in 10D5 mAb treated $\mathrm{APP} / \varepsilon 2$ and $\mathrm{APP} / \varepsilon 3$ mice $(p<0.0001)$, while the $\mathrm{CD} 68 /$ Th-S ratio was $1.33(p<0.0001)$ and $1.21(p<0.01)$ fold higher, respectively (Fig. 3c, f).

Using the combination of anti-Iba1 immunostaining and Th-S counterstaining enabled us also to analyze morphology of microglia across $A P O E$ genotypes and treatment arms. Microglia associated with fibrillar plaques displaying features of activated microglia/macrophage ie. enlargement and rounding of the perikaryon and shortening of processes to their nearly disappearance, were observed in untreated age-matched and TY11-15 controls of all APOE backgrounds (Fig. 3a). 10D5 mAb treatment was associated with increased periplaque microglia recruitment and enhancement of its morphological activation features. This effect was significantly more pronounced in $\mathrm{APP} / \varepsilon 4$ mice than in other genotypes (Fig. 3a). In parallel to peri-plaque localization of activated microglia demonstrated by antiIba1 immunostaining, there also was noticeable peri-plaque localization of anti-CD68 immunostaining, which highlights lysosomal component of activated microglia/macrophages (Fig. 3d). Akin to Iba1 expression the peri-plaque expression of CD68 antigen increased with 10D5 mAb treatment across $A P O E$ genotypes but the increase was the most pronounced in $10 \mathrm{D} 5$ treated $\mathrm{APP} / \varepsilon 4$ mice. Peri-plaque recruitment of Iba1 positive activated microglia/macrophages and accompanying upsurge of CD68 expression in 10D5 $\mathrm{mAb}$ treated mice was associated with reduced plaque diameter as demonstrated by double anti-Iba1/Th-S and anti-CD68/Th-S stainings (Fig. 3a, d). We also observed Iba1 positive activated microglia and CD68 positive puncta, which were dissociated from Th-S positive plaque. They likely define activated microglia engaged with diffuse, immnunopositive $A \beta$ plaques lacking fibrillar component. Their load also became markedly increased with 10D5 mAb treatment.

\section{$A P O E$ genotype has strong differential effect on VA $\beta$ burden and its reduction with $A \beta$ immunotherapy}

Two forms of $\mathrm{A} \beta$ angiopathy were observed in brains of $A P O E$ targeted replacement $\mathrm{APP}_{\mathrm{SWE}} / \mathrm{PS}_{\mathrm{dE} 9}$ mice and they were analyzed separately. The first type was CAA defined as Th-S positive deposits of fibrillar $A \beta$ in walls of meningeal arteries and arteries penetrating the brain cortex (Fig. 4a). CAA load was quantified in the brain cortex on Th-S stained sections and defined as the percent of the cross-sectional area of the cortex occupied by CAA laden vessels. The second type of $A \beta$ angiopathy concerned immunoreactive $A \beta$ deposits along walls of capillary vessels, which were Th-S negative (CCA) (Fig. 5a). CCA incidence was analyzed by calculating a number of $A \beta$ immunopositive capillary profiles per $\mathrm{mm}^{2}$ in the brain cortex where they appeared in abundance across all $A P O E$ genotypes. In addition, CCA was analyzed in the thalamus as in APP/ $\varepsilon 2$ mice it was associated with outstanding number of perivascular hemosiderin deposits.

There was no significant difference in the CAA load between untreated age-matched and TY11-15 control mice for each of $A P O E$ genotypes analyzed. However across the TY11-15 control groups, APP/ 44 mice showed two fold higher CAA load than APP $/ \varepsilon 3$ mice $(\mathrm{p}<0.01)$ (Fig. 4a, b). In contrast to $\mathrm{APP} / \varepsilon 3$ and $\mathrm{APP} / \varepsilon 4$ lines, in $\mathrm{APP} / \varepsilon 2$ mice CAA laden arteries were rarely occurring and were present in only some of the mice which precluded reliable quantification of the CAA load in this genotype (Fig. 4a). CAA laden vessels were rarely and inconsistently observed in the hippocampus and in subcortical structures including the thalamus in mice of any $A P O E$ genotype. 10D5 $\mathrm{mAb}$ treatment reduced the CAA load in the brain cortex in $\mathrm{APP} / \varepsilon 3$ and $\mathrm{APP} / \varepsilon 4$ mice by $56 \%(p<0.05)$ and $71 \%(p$ $<0.01)$ relative to the mean CAA load value in TY11-15 controls of corresponding genotypes. However, given significantly higher CAA load baseline in APP/ $/ 4$ mice the absolute CAA load reduction in APP/ $/ \varepsilon 4$ mice was 2.5 fold higher than that in $\mathrm{APP} / \varepsilon 3$ mice. Thus, the CAA load in $\mathrm{APP} / \varepsilon 4$ animals was reduced from $0.41 \pm 0.03 \%$ in TY1115 controls to $0.11 \pm 0.02 \%$ in $10 \mathrm{D} 5 \mathrm{mAb}$ treated group 

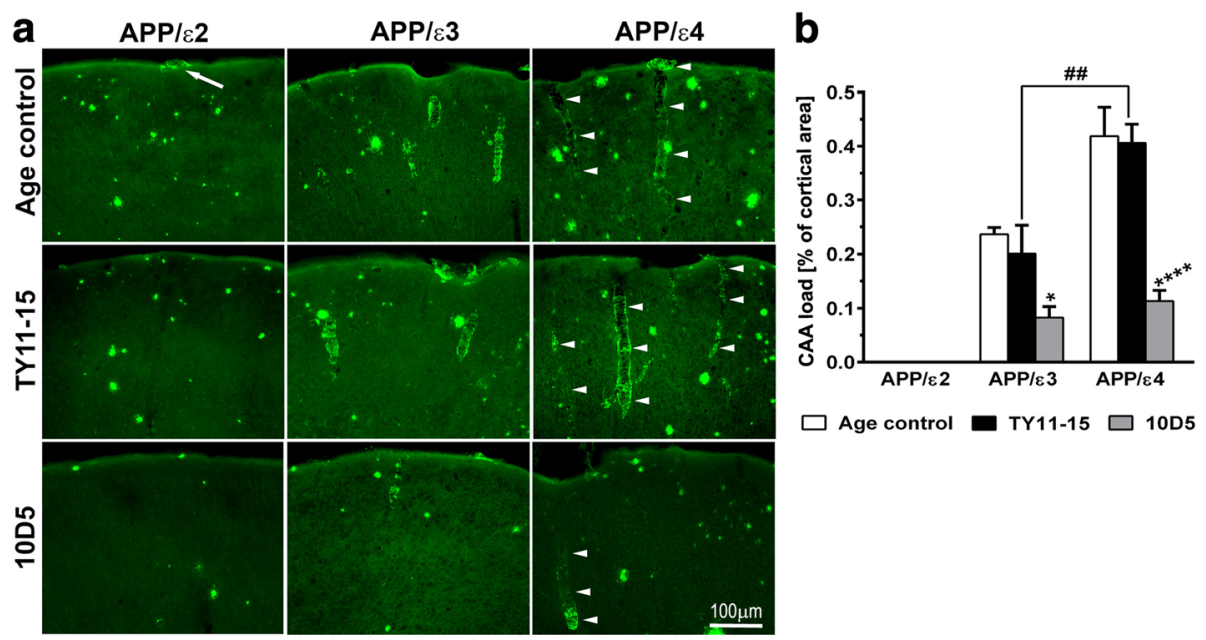

Fig. 4 CAA analysis. APOE genotype differentially modulates the CAA load and its reduction during 10D5 mAb immunization. a Demonstration of CAA across APOE genotype spectrum. Representative microphotographs of Th-S stained coronal brain sections through the somatosensory cortex from untreated age-matched (Age control) mice, and mice receiving TY11-15 an isotype control lgG2a antibody or 10D5 anti-AB mAb. An arrow indicates a solitary CAA positive vessel in Age control APP/ع2 mouse. Arrowheads show long segments of CAA laden vessels in APP/ع4 mice and their reduction with 10D5 mAb treatment. b Mean ( \pm SEM) of CAA load quantified in the brain cortex ( $n=8-12 / g r o u p)$. (b) $p<0.0001$ (one-way analysis of variance); ${ }^{*} p<0.05$, and ${ }^{* * *} p<0.0001$, TY11-15 control vs. $10 \mathrm{D} 5 \mathrm{mAb}$ treatment for matching APOE genotypes (Sidak's post hoc test). $\# p<0.01, A P P / \varepsilon 4$ TY11-15 control vs. APP/ع3 TY11-15 control (Sidak's post hoc test). Differences between Age control and TY11-15 groups were non-significant for matching APOE genotypes (Sidak's post hoc test); not shown on the graph. Scale bar $100 \mu \mathrm{m}(\mathbf{a})$

(absolute CAA load reduction $=0.30 \%$ ) while in $\mathrm{APP} / \varepsilon 3$ mice the absolute reduction in the CAA load was $0.12 \%$.

Unlike CAA, which was the most prevalent in APP/\&4 mice, the greatest abundance of CCA was associated with the APOE $\varepsilon 2$ allele (Fig. $5 \mathrm{a}-\mathrm{c}$ ). The density of CCA associated capillary profiles per $\mathrm{mm}^{2}$ in the brain cortex of APP/ $\varepsilon 2$ TY11-15 control mice was 1.9 and 1.3 fold higher than these in the brain cortex of APP/ع3 $(p<0.0001)$ and APP/ $\varepsilon 4(p<0.05)$ TY11-15 controls, respectively; while in the thalamus of APP/ع2 TY11-15 controls the average density of CCA associated capillary profiles per group was 13.1 and 5.3 fold higher than in the thalamus of APP/ $\varepsilon 3(p<0.0001)$ and APP/ $\varepsilon 4(p<0.001)$ TY11-15 control mice, respectively. There was no statistically significant difference in the CCA incidence between untreated age-matched and TY11-15 control mice in the brain cortex and in the thalamus for any of matching $A P O E$ genotype. One needs to mention that CCA was absent in the thalamus of two thirds of control APP $/ \varepsilon 3$ mice and of one half of control APP $/ \varepsilon 4$ mice. Besides the thalamus, the incidence of CCA in other subcortical structures was scanty especially in $\mathrm{APP} / \varepsilon 3$ and $\mathrm{APP} / \varepsilon 4$ mice, thus no other structure specific quantification was performed.

10D5 mAb treatment effected significant CCA reduction across all three $A P O E$ genotypes. In the brain cortex of $\mathrm{APP} / \varepsilon 2$ and $\mathrm{APP} / \varepsilon 3$ mice the density of $\mathrm{A} \beta$ immunopositive capillary profiles was reduced approximately two-fold ( $p<0.001$ and $p<0.05$; respectively), while in the brain cortex of $\mathrm{APP} / \varepsilon 4$ mice it was reduced by 1.6 fold $(p<0.05)$.
10D5 mAb treatment reduced CCA in the thalamus of $\mathrm{APP} / \varepsilon 2$ mice 8.5 fold $(p<0.0001)$. Marked reduction also was observed in the thalamus of $\mathrm{APP} / \varepsilon 3$ and $\mathrm{APP} / \varepsilon 4$ mice, but it did not reach statistical significance as the data did not conform to normal distribution hence weaker nonparametric statistical analysis was used.

\section{$A P O E \varepsilon 2$ and $\varepsilon 3$ alleles show opposing effect on the risk of cerebral microhemorrhages}

Perivascular hemosiderin deposits, reflecting ensued microhemorrhages, were found associated both with CAA and CCA positive vessels (Fig. 6a, b). They frequently occurred in untreated age-matched mice of all $A P O E$ genotypes and their number did not increase in TY11-15 treated control animals (Fig. 7a-d). There were no statistically significant differences in the number of the total brain hemosiderin deposits, the number of deposits subclassified as small and large (with cut off $\geq 15 \mu \mathrm{m}$ in diameter), and the fraction of deposits localized to the

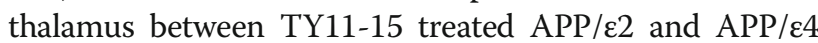
mice (Fig. 7a-d). In contrast, untreated age-matched and TY11-15 APP/ع3 control mice had approximately twofold less hemosiderin deposits for each listed category compared to APP/\&2 and APP/\&4 TY11-15 controls.

$10 \mathrm{D} 5 \mathrm{mAb}$ treatment resulted in a significant increase in the number of hemosiderin deposits yet the magnitude of this effect was differentially modulated by the $A P O E$ genotype. In $\mathrm{APP} / \varepsilon 3$, and $\mathrm{APP} / \varepsilon 4$ mice, an increase by 12.4 and 15.6 deposits per brain on average was observed, 


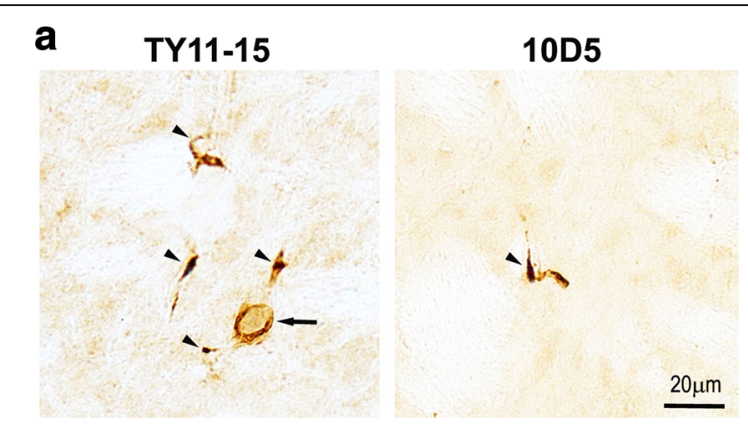

b

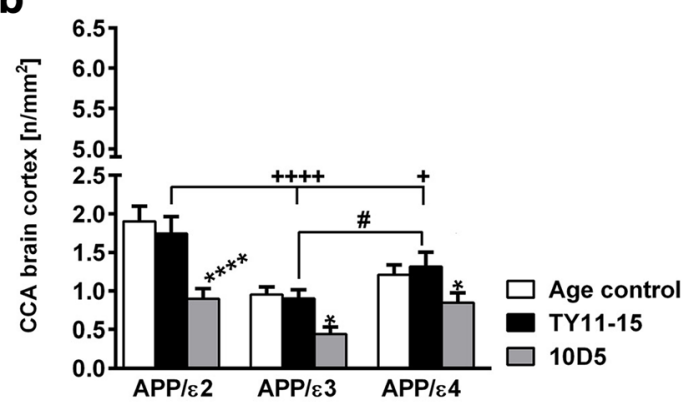

C

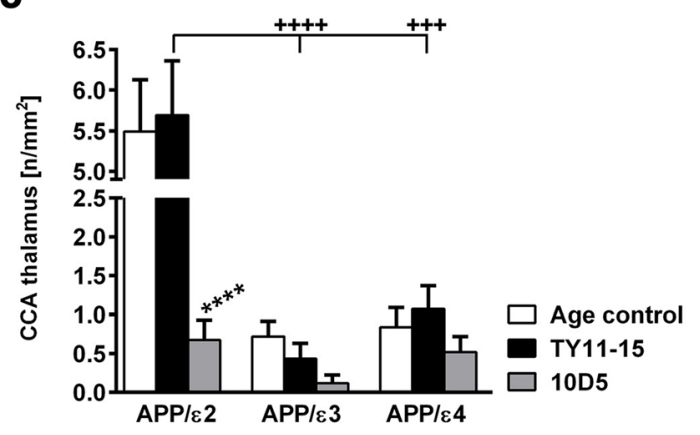

Fig. 5 Characterization of CCA. The APOE $\varepsilon 2$ allele is associated with increased CCA incidence. a Demonstration of CCA in the thalamus of APP/ع2 mice receiving TY11-15 isotype control lgG2a antibody or 10D5 anti-A $\beta$ mAb. Arrowheads indicate numerous $A \beta$ immunopositive capillary vessels ( $<8 \mu \mathrm{m}$ in diameter). An arrow in the left panel points at the vessel, which wall is also $A \beta$ immunopositive, but which was not counted as a capillary as its diameter exceeded the assumed capillary size cutoff. There is noticeable reduction in the density of $A \beta$ immunoreactive capillaries following $10 \mathrm{D} 5 \mathrm{mAb}$ treatment shown on the right panel. Quantitative analysis of CCA. Shown are means ( \pm SEM) for counts of $A \beta$ immunopositive capillaries per $\mathrm{mm}^{2}$ in the brain cortex (b) and the thalamus (c) from 5-8 brains per APOE genotype and 3 sections per brain. $p<0.0001$ (one-way analysis of variance) in (b) and $p<0.0001$ (Kruskal-Wallis $\mathrm{H}$ test) in $(\mathbf{c}) ;{ }^{*} p<0.05$, and ${ }^{* * *} p<0.0001$, TY11-15 control vs. 10D5 mAb treatment for matching APOE genotypes (Sidak's post hoc test in [b] and Dunn's multiple comparison post hoc test in $[\mathbf{c}]) .{ }^{+} p<0.05,{ }^{+++} p<0.001$ and ${ }^{++++} p$

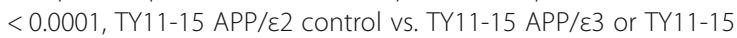
APP/\&4 control groups (Sidak's post hoc test in $[\mathbf{b}]$ and Dunn's multiple comparison post hoc test in [c] ]. ${ }^{\#} p<0.05$ in (b), TY11-15 APP/ع3 control vs. TY11-15 APP/ع4 control (Sidak's post hoc test). Differences between Age control and TY11-15 control for matching $A P O E$ genotypes in (b) and (c) were non-significant; not shown on the graph. Scale bar $20 \mu \mathrm{m}(\mathbf{a})$ respectively; bringing their number in $\mathrm{APP} / \varepsilon 3$ mice from $20.5 \pm 1.9$ per brain in TY11-15 controls to $32.9 \pm 3.8$ per brain in 10D5 mAb treatment group $(p<0.05)$, while in APP/ $\varepsilon 4$ mice, from $41.1 \pm 4.6$ per brain in TY11-15 controls to $56.7 \pm 4.1$ per brain in the 10D5 mAb treatment group $(p<0.01)$ (Fig. 7a). The increase only concerned small deposits (Fig. 7b), while the number of large deposits did not change in either APP $/ \varepsilon 3$ or APP $/ \varepsilon 4$ mice (Fig. $7 b, c)$. Differences in the number of all hemosiderin deposits and small hemosiderin deposits between 10D5 mAb treated APP/ع3 and $\mathrm{APP} / \varepsilon 4$ mice were statistically significant $(p<0.0001$ and $p<0.01$, respectively) (Fig. $7 \mathrm{a}, \mathrm{b}$ ). In $\mathrm{APP} / \varepsilon 2$ mice 10D5 mAb treatment caused a nearly two-fold higher upsurge in the number of hemosiderin deposits compared to $\mathrm{APP} / \varepsilon 3$ and APP/ $/ \varepsilon 4$ mice. The count of all hemosiderin deposits was increased on averaged by 27.0 per brain bringing it from $42.5 \pm 3.8$ per brain in TY11-15 controls to $69.5 \pm$ 4.4 per brain in 10D5 mAb treated group $(p<0.0001)$ (Fig 7a, b). Unlike other APOE genotypes, APP/ع2 mice experienced an increase both in the number of small and large hemosiderin deposits. The count of large hemosiderin deposits was increased on average by 7.3 per brain from $3.7 \pm 0.9$ in TY11-15 controls to $11.0 \pm 1.4$ in 10D5 treated mice (a nearly three-fold increase) $(p<0.0001)$ (Fig 7c).

The bulk of perivascular hemosiderin deposits was found in the brain cortex (Additional file 2: Figure S2 A-C). In Age control and TY11-15 control APP/ $/ \varepsilon 3$ and APP/ $/ \varepsilon 4$ mice they constituted between 65 to $70 \%$ of the brain total hemosiderin deposits, while in Age control and TY11-15 control APP/ $/ 22$ mice $53 \%$ and $58 \%$, respectively. As compared to other $A P O E$ genotypes $\mathrm{APP} / \varepsilon 2$ mice showed greater number of hemosiderin deposits to the thalamus. In $\mathrm{APP} / \varepsilon 2 \mathrm{TY} 11-15$ control mice $14.9 \pm 2.8 \%$ of all brain hemosiderin deposits was found in the thalamus compared to $5.1 \pm 1.9 \%$ in TY11-15 APP/ $/ 3$ controls $(p<0.05)$ and 12.3 $\pm 3.1 \%$ in TY11-15 APP/ $\varepsilon 4$ controls (non-significant) (Fig. 7d). While in APP/ع3 and APP/ع4 mice 10D5 mAb treatment did not affect the proportion of thalamic hemosiderin deposits to all brain deposits, in 10D5 mAb treated $\mathrm{APP} / \varepsilon 2$ mice this proportion nearly doubled and it was $27.7 \pm 3.6 \%$ on average $(p<0.0001)$ (Fig. $7 \mathrm{~d}$; Additional file 2: Figure S2 A). Except for minor increase in the number of hemosiderin deposits in the hippocampus in APP/ع2 mice, no other brain structure but the brain cortex in animals of all $A P O E$ genotypes and the thalamus in $\mathrm{APP} / \varepsilon 2$ mice only, showed significant regional increase in the number of hemosiderin deposits with anti-A $\beta$ passive immunization (Additional file 2: Figure S2 A-C).

\section{APOE alleles have differential effect on cerebrovascular disease risk factors in $\mathrm{APP}_{\mathrm{SWE}} / \mathrm{PS}_{\mathrm{dEg}}$ mice}

$A P O E$ \&2 targeted replacement mice are established model of type III hyperlipidemia. APP/ $\varepsilon 2$ TY11-15 control mice used in this study showed average total serum 


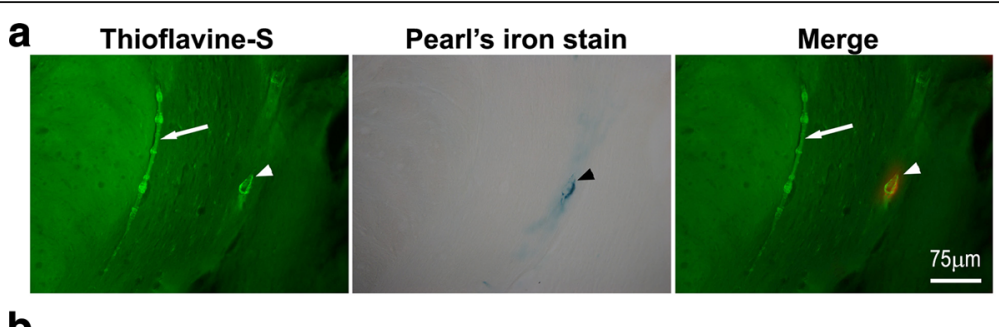

b

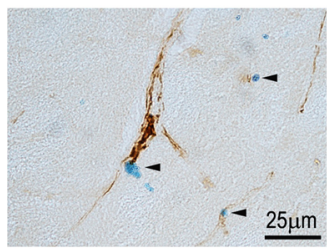

C

TY11-15

10D5

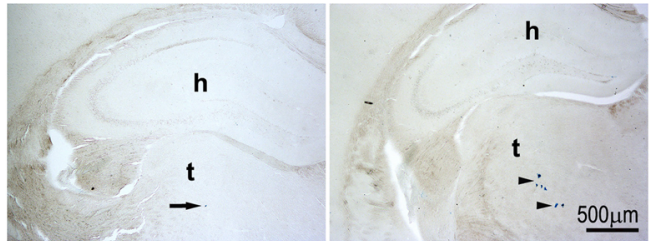

Fig. 6 Demonstration of perivascular hemosiderin deposits reflecting ensued microhemorrhages. a Shown is an example of hemosiderin deposition associated with CAA laden vessel in the cerebral cortex of 10D5 mAb treated APP/ع4 animal. The histological section was double-stained with Thioflavin-S and Pearls' Prussian blue stain for ferric iron and photographed under fluorescence and bright-field microscopy, respectively. Positive perivascular hemosiderin stain (arrowhead) was digitally converted to red color and superimposed on green Thioflavin-S stain of CAA (Merge). An arrow indicates a vessel affected by CAA, without evidence of bleeding. $\mathbf{b}$ Representative microphotograph of CCA related hemosiderin deposits (arrowheads) in the brain cortex of $10 D 5$ mAb-treated APP/E2 mouse. A coronal section of the cerebral cortex was immunostained with anti-AB HJ3.4 mAb and counterstained with Pearls' Prussian blue stain. c Examples of large hemosiderin deposits in the thalamus typical of APP/ع2 mice; Pearl's iron stain without counterstain. An arrow on the left panel indicates an isolated thalamic hemosiderin deposit in TY11-15 control APP/ع2 animal, while arrowheads on the right panel point at the cluster of large hemosiderin deposits ( $\geq 15 \mu \mathrm{m}$ in diameter) identified in 10D5 mAb treated APP/ع2 mouse. Abbreviations: h-hippocampus, t-thalamus. Scale bars: $75 \mu \mathrm{m}$ (a), $25 \mu \mathrm{m}$ (b), $500 \mu \mathrm{m}$ (c)

cholesterol level of $477.3 \pm 49.5 \mathrm{mg} / \mathrm{dl}$ at the age of 15 months. For comparison total serum cholesterol level in TY11-15 control APP/ع3 and APP/ $/ \varepsilon 4$ mice was $83.8 \pm$ $4.7 \mathrm{mg} / \mathrm{dL}$ and $97.9 \pm 7.7 \mathrm{mg} / \mathrm{dL}$, respectively $(p<0.0001$ vs. APP/ع2) (Fig. 8a ). APP/ع2 mice were also obese. The average weight of APP/ع2 TY11-15 control mice was 46.6 $\pm 0.8 \mathrm{~g}$, while average weight of TY11-15 control APP/ع3 and $\mathrm{APP} / \varepsilon 4$ mice was $33.6 \pm 1.6 \mathrm{~g}$ and $35.9 \pm 1.5 \mathrm{~g}$, respectively ( $p<0.0001$ vs. APP/ $/ 2$ ) (Fig. $8 \mathrm{~b})$. Neither serum cholesterol level nor animal weight was significantly changed with 10D5 mAb treatment. No significant differences in respect to total serum cholesterol level and animal body weight between untreated age-control and TY11-15 control mice for matching $A P O E$ genotypes were observed.

\section{Discussion}

$A P O E$ genotype critically affects the burden of $\mathrm{A} \beta$ pathology in sporadic AD. ApoE isoforms encoded by various $A P O E$ alleles differentially influence the rate of soluble $\mathrm{A} \beta$ clearance from the brain interstitial space and formation of $\mathrm{A} \beta$ parenchymal plaques and $\mathrm{VA} \beta[32,33]$. Our study provides novel evidence that $A P O E$ genotype also differentially affects multiple aspects of response to $A \beta$ immunotherapy. Firstly, we observed that $A P O E$ genotype is associated with variable reduction in the load of $A \beta$ parenchymal plaques and $\mathrm{APP} / \varepsilon 4$ mice had greater reduction in absolute $\mathrm{A} \beta$ plaque load values than $\mathrm{APP} / \varepsilon 2$ and $\mathrm{APP} /$ $\varepsilon 3$ mice. The reduction concerned both Th-S positive, (fibrillar) and immunopositive $A \beta$ (total) plaque loads with the later metric showing greater change than the former across all $A P O E$ genotypes. As the immunopositive $\mathrm{A} \beta$ plaque load is inclusive of Th-S positive plaques this suggests that stimulated by 10D5 mAb microglia clear diffuse component of $A \beta$ plaques more effectively than they do fibrillar $A \beta$ aggregates. However, despite enhanced treatment effect in $\mathrm{APP} / \varepsilon 4$ mice the post-treatment $\mathrm{A} \beta$ plaque load in these mice and especially the fibrillar $A \beta$ plaque load, remained significantly higher than in APP/ $/ 22$ and $\mathrm{APP} / \varepsilon 3$ mice, what is a result of distinguishably greater $A \beta$ plaque load, associated with the $\varepsilon 4$ allele. This observation may inform design of future passive immunization experiments in APP Tg model mice of AD and clinical trials suggesting specific tailoring of the anti$\mathrm{A} \beta$ passive immunization protocol in $A P O E$ \&4 allele 

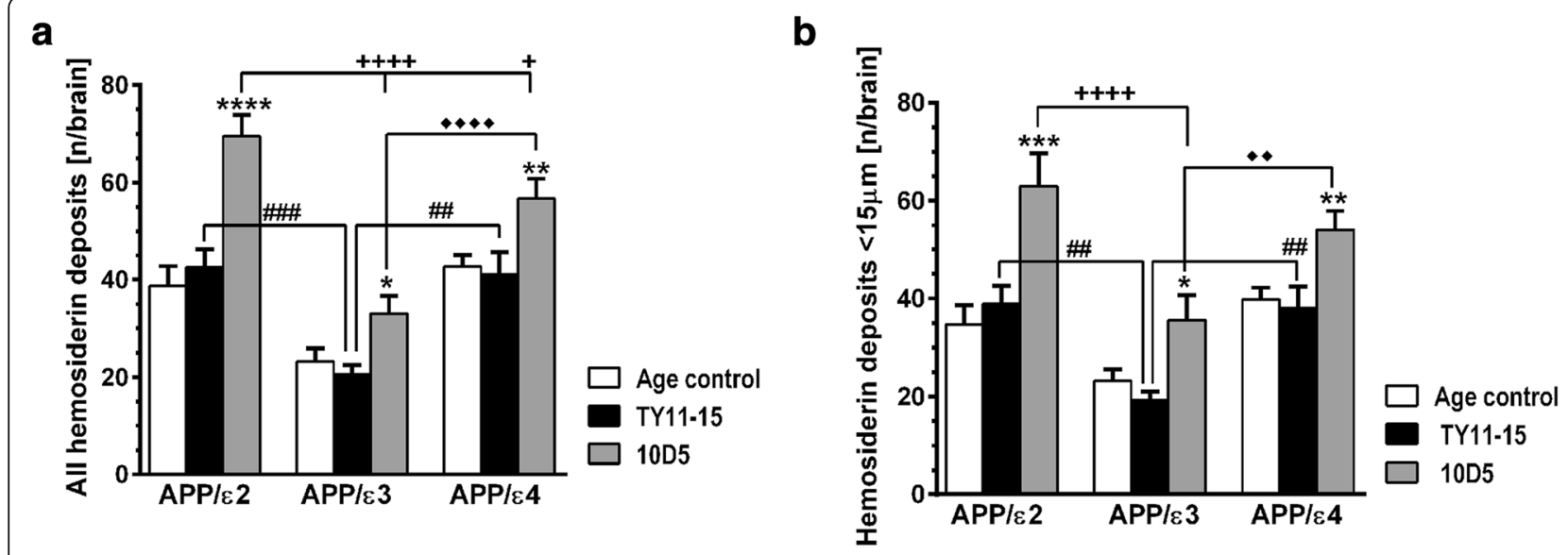

C

d
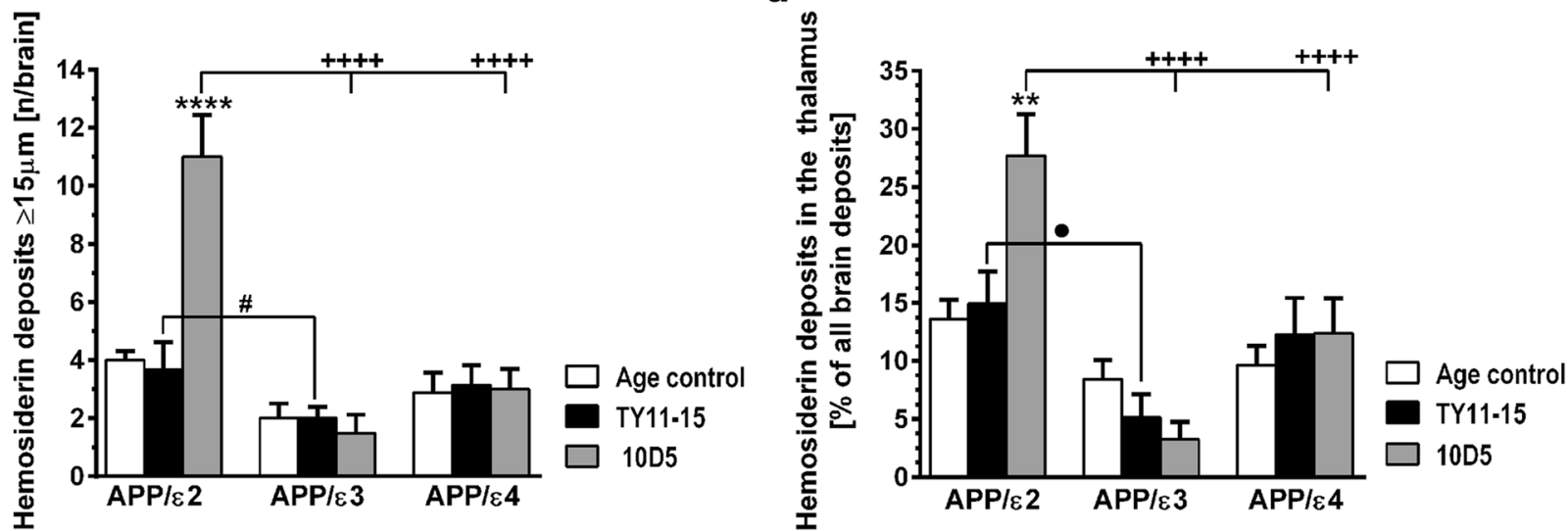

Fig. 7 Quantitative analysis of perivascular hemosiderin deposits. APOE genotype differentially modulates occurrence of hemosiderin deposits and their increase during $A \beta$ immunotherapy with $A P O E \varepsilon 2$ and $A P O E \varepsilon 3$ alleles having adverse and protective effects, respectively. Shown are means $( \pm$ SEM) for counts of all brain perivascular hemosiderin deposits (a), small perivascular hemosiderin deposits $(<15 \mu m$ in diameter) (b), large perivascular hemosiderin deposits ( $\geq 15 \mu \mathrm{m}$ in diameter) (c), and perivascular hemosiderin deposits in the thalamus presented as per cent of all brain deposits (d) ( $n=5-11 /$ group). Hemosiderin deposits were counted on every tenth brain coronal cross-section along the entire rostro-caudal axis of the brain. (a) through (d) $p<0.0001$ (one-way analysis of variance); ${ }^{*} p<0.05,{ }^{* *} p<0.01,{ }^{* *} p<0.001$, and ${ }^{* * *} p<0.0001$, TY11-15 control vs. $10 \mathrm{D} 5 \mathrm{mAb}$ treatment for matching APOE genotypes (Sidak's post hoc test). ${ }^{+} p<0.05$, and ${ }^{++++} p<0.0001,10 \mathrm{D} 5 \mathrm{mAb}$ treated APP/ع2 mice vs. other $10 \mathrm{D} 5 \mathrm{mAb}$

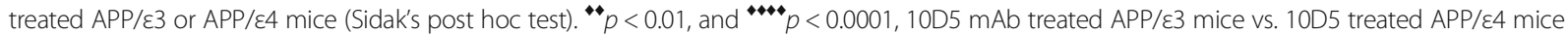
(Sidak's post hoc test). $p<0.05$ APP/ع2 TY11-15 control vs. APP/ع3 TY11-15 control (Sidak's post hoc test). Differences between Age control and TY11-15 groups were non-significant for all types of hemosiderin deposits for matching APOE backgrounds, so were differences in the count of large hemosiderin deposits between TY11-15 control and 10D5 mAb treated APP/ع3 and APP/ع4 mice (Sidak's post hoc test); not shown on the graph

carriers to achieve end-point plaque load reduction level compared to that expected among non- $\varepsilon 4$ allele carriers. Potential modifications of the immunization protocol may include increasing antibody dose, earlier commencement of the treatment and extension of treatment duration. However one needs to be mindful that escalation of anti$\mathrm{A} \beta \mathrm{mAbs}$ dose in $A P O E$ \&4 allele carriers may trigger increased rate of vasculotropic adverse events associated with immunization $[5,8,14]$. With the advancement of certain newer anti-A $\beta$ immunotherapies such as Gantanerumab and Aducanumab that appear to lower $A \beta$ plaque load in humans to a greater extent than seen previously $[6,8]$, it will be interesting to see if the effects of $A P O E$ genotype noted here in animal models are also present in humans.

The primary mechanism of action of $10 \mathrm{D} 5 \mathrm{mAb}$ is based on its direct binding to deposited $\mathrm{A} \beta$ and stimulating Fc receptor-mediated $A \beta$ plaque removal by activated microglia and possibly blood derived macrophages $[9,34]$. To compare microglial response across $A P O E$ genotypes we immunostained brain sections against Iba1 and CD68 antigens and counterstained them with Th-S for fibrillar $A \beta$. Iba1 is a microglia specific marker, which expression increases with microglia activation and macrophage 


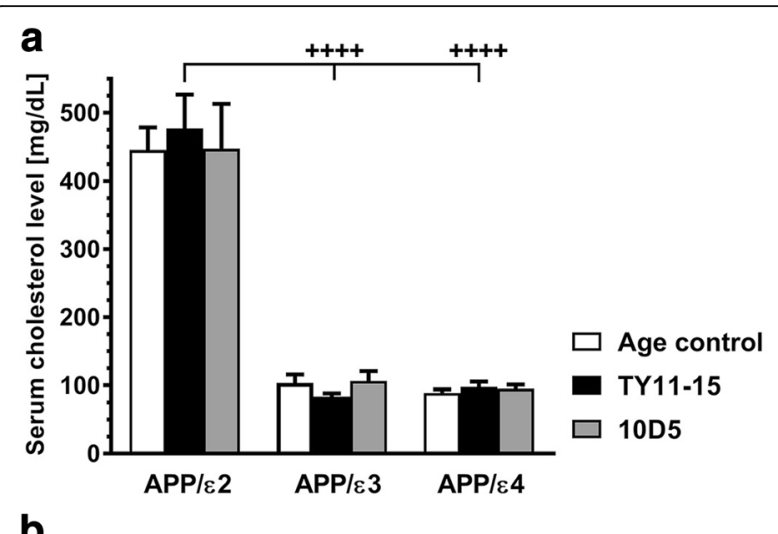

b

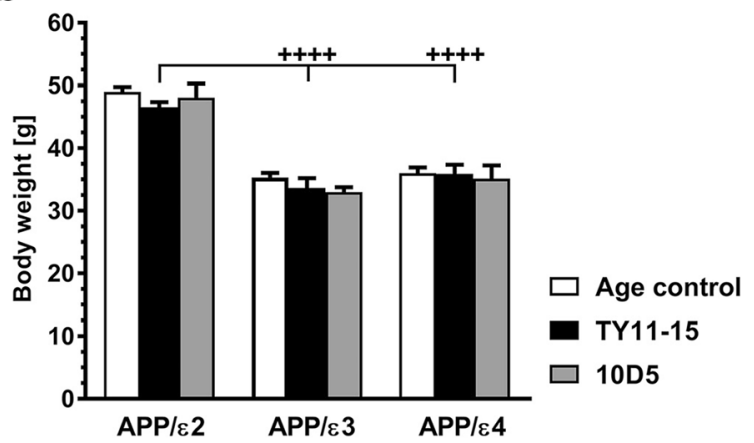

Fig. 8 Analysis of cerebrovascular disease risk factors. APP/ع2 mice show hypercholesterolemia and obesity. Mean \pm SEM of the total serum cholesterol level (a) ( $n=5-10 /$ group) and body weight (b) ( $n=6-16 /$ group) of untreated Age control, TY11-15 treated control, and 10D5 mAb treated mice determined at the age of 15 months at the conclusion of the experiment. $\mathbf{a}$ and $(\boldsymbol{b}) p<0.0001$ (one-way analysis of variance); ${ }^{+++} p<0.0001$, TY11-15 APP/ع2 vs. TY11-15 APP/ $\varepsilon 3$ and APP/\&4 control mice (Sidak's post hoc test). Differences between Age control, TY11-15 control, and 10D5 mAb treated mice were non-significant for matching APOE backgrounds (Sidak's post hoc test); not shown on the graph

transformation [30], while CD68 is a lysosomal/endosomal membrane glycoprotein up regulated in actively phagocytic cells [31]. The load of Iba1 and CD68 positive cells was significantly higher in Age control and TY11-15 control $\mathrm{APP} / \varepsilon 4$ mice compared to $\mathrm{APP} / \varepsilon 2$ and $\mathrm{APP} / \varepsilon 3$ controls. Both Iba1 and CD68 loads correlated with the load of Th-S positive fibrillar deposits and when adjusted for it, they were comparable across all $A P O E$ genotypes in control animals. Following 10D5 mAb treatment both Iba1 and CD68 loads increased across all $A P O E$ genotypes, however when adjusted for the post-treatment fibrillar plaque load, they were significantly higher in $\mathrm{APP} / \varepsilon 4$ mice than in $\mathrm{APP} / \varepsilon 2$ and $\mathrm{APP} / \varepsilon 3$ animals. This finding illustrates increased effector function of 10D5 mAb exerted on microglia in the setting of the $A P O E \& 4$ allele. In particular exaggerated post treatment $\mathrm{CD} 68 / \mathrm{Th}-\mathrm{S}$ ratio in $\mathrm{APP} / \varepsilon 4$ mice implies less effective $A \beta$ degradation, which can be tied to a recent discovery showing that excessive apoE accumulation within $A \beta$ plaques impairs ability of microglia to contain plaque load [35]. In fact, we have previously demonstrated that $\mathrm{APP} / \varepsilon 4$ and $\mathrm{PDAPP} / \varepsilon 4$ mice have greatly increased content of apoE within $A \beta$ deposits compared to the same Tg mice lines expressing other human $A P O E$ alleles $[19,36]$. Though microglial cells play pivotal role in maintaining immunoproteostasis through phagocytosis and degradation of misfolded proteins, their protective function is inseparably associated with immune activation exerting a chronic, potentially harmful effect on the regional milieu of neuronal networks [35, 37-39]. Although, APP/\&4 mice show the greatest absolute reduction in the load of parenchymal $A \beta$ plaques in response to anti-A $\beta$ immunization as compared to mice of other $A P O E$ genotypes, this occurs at the expense of unparalleled microglia response making the post treatment Iba1 and CD68 loads the highest among all experimental groups. Thus both higher level of microglia activation driven by higher $A \beta$ plaque load and exaggerated microglia effector response exerted by anti-A $\beta$ immunotherapy may constitute independent deleterious effects associated with the $\varepsilon 4$ allele, in $\mathrm{AD}$ pathogenesis. Increased microglia activation and associated reduction in $\mathrm{A} \beta$ plaque load was found only in 10D5 mAb immunized groups, while administration of the isotype control antibody TY11-15 changed neither expression of microglia markers nor parenchymal plaque load as compared to untreated agematched animals of matching APOE genotypes.

Both CAA and CCA variants of VA $\beta$ pathology have been described in $\mathrm{AD}$ autopsies and their relative preponderance has been linked to various $A P O E$ genotypes [4043]. CAA comprises of fibrillar $A \beta$ sandwiched between the adventitia and the tunica media of cerebral arteries, while CCA comprises of non-fibrillar A $\beta$ deposits closely associated with the capillary outer basement membrane. Both development of CAA and CCA is primarily driven by neuron derived $A \beta$, while $A \beta$ produced by myocytes locally in the tunica media further contributes to CAA development (reviewed in [42]). Presence of apoE within CAA lesions is critical for formation of $A \beta$ fibrillar assemblies [25]. In this study we found that $A P O E$ genotype modulates development of both CAA and CCA pathology in APP Tg mice. In accordance to previously published data concerning $\varepsilon 4$ allele effect, we found increased CAA load in APP/ $\varepsilon 4$ mice [25, 44-46]. Our novel observation here is that the $\varepsilon 2$ allele was associated with greatly reduced CAA load, but also with enhanced incidence of CCA. Reduced CAA load in $\mathrm{APP} / \varepsilon 2$ mice likely reflects limited effect of apoE2 isoform on promoting $A \beta$ fibrillar assemblies within arterial walls as compared to other human apoE isoforms, which are associated with higher load of CAA and fibrillar $\mathrm{A} \beta$ plaques [47]. In turn, greater incidence of CCA may be related to increased amount of soluble $A \beta$ cleared across the $\mathrm{BBB}$ in $\mathrm{APP} / \varepsilon 2$ animals, which deposit less $\mathrm{A} \beta$ in the brain while maintaining the same level of $A \beta$ production [32]. In 
fact increased rate of soluble $A \beta$ clearance across the $B B B$ has been experimentally confirmed in the setting of the $A P O E$ \&2 allele [32, 48]. Vascular disease risk factors including hypercholesterolemia and volume overload occurring in aged $\mathrm{APP} / \varepsilon 2$ mice effect deterioration of capillary wall structure and function and likely in tandem with greater load of soluble $A \beta$ passing across the BBB contribute to CCA development.

The largest percentage of $\mathrm{AD}$ patients with both CAA and CCA was found among $\varepsilon 4$ allele carriers, while CAA without CCA was more frequent among $\varepsilon 2$ and $\varepsilon 3$ carriers $[40,42]$. In these studies $\varepsilon 3$ allele carriers and in particular $\varepsilon 3$ allele homozygotes constituted the largest percentage among CAA/CCA free cases. Accordingly, we found that $\mathrm{APP} / \varepsilon 3$ mice have the lowest incidence of CCA among all APOE genotypes and their CAA load is significantly lower than that in $\mathrm{APP} / \varepsilon 4$ mice demonstrating protective effect of the $\varepsilon 3$ allele against development of $A \beta$ angiopathy. However, mechanisms underlying VA $\beta$ deposition including preferential development of CAA and CCA remain elusive and require further elucidation. They likely are a resultant of multiple genetic features extending beyond $A P O E$ genotype as no $A P O E$ allelic variant confers absolute protection against VA $\beta$ deposition [42, 43].

VA $\beta$ is detrimental to the function of cerebrovascular circulation through compromising blood-brain-barrier integrity [49], effecting hemodynamic dysfunction [29, 50], and facilitating occurrence of spontaneous hemorrhages $[25,26,36]$. We found a significant number of perivascular hemosiderin deposits, reflecting ensued microhemorrhages, in brains of control mice representing all $A P O E$ genotypes. They were associated both with CAA and CCA affected vessels. Strikingly the lowest incidence of perivascular hemosiderin deposits was observed among untreated age-matched and TY11-15 control $\mathrm{APP} / \varepsilon 3$ mice. In $\mathrm{APP} / \varepsilon 4$ and $\mathrm{APP} / \varepsilon 2$ controls the incidence of perivascular hemosiderin deposits was comparable and statistically significant higher than that in $\mathrm{APP} / \varepsilon 3$ controls. In human subjects prevalence of spontaneous microhemorrhages is high and positively correlates with advancing age. MRI studies detected microbleeds in $17.8 \%$ of subjects aged $60-69$ years and in $38.3 \%$ in subjects who were more than 80 years old [51, 52]. For comparison an autopsy study reported histological evidence of ensued microhemorrhages in $92.9 \%$ of elderly individuals with mean age of $81.1 \pm$ 10.8 years, which included both $\mathrm{AD}$ and non-demented subjects [53]. Evidence independently supports link of both the $A P O E \& 4$ and $\varepsilon 2$ allele with increased risk for microhemorrhages in humans [51, 52, 54-57]. Both VA $\beta$ and hypertensive or atherosclerotic microangiopathy are recognized clinical risk factors for cerebral microbleeds, with the former correlating stronger with bleeding in cortical/subcortical distribution [58, 59] while the later with bleeding to deep brain structures including basal ganglia and thalamic nuclei [60, 61]. APOE $\varepsilon 2$ targeted replacement mice develop type III hyperlipoproteinemia and spontaneous atherosclerosis [16] as well as volume overload as a function of their obesity, all of which are recognized vascular risk factors and may explain increased preponderance to thalamic localization of hemosiderin deposits in $\mathrm{APP} / \varepsilon 2$ mice found in our study. However, these striking vasculotropic effects observed here in $\mathrm{APP} / \varepsilon 2$ mice may not be robustly seen in human subjects, where $\varepsilon 2$ homozygotes constitute only $1 \%$ of the population, with less than $10 \%$ of them developing type III hyperlipoproteinemia, what is linked to distinctly different contribution of apoE to VLDL formation between humans and mice [62].

$A \beta$ immunotherapy can ameliorate VA $\beta$ burden and improve compromised vascular reactivity $[12,21,63]$, but it is well known to escalate incidence of brain microhemorrhages [21, 26]. Both CAA load and CCA incidence were reduced in 10D5 mAb treated mice with the strongest effect on CAA load reduction seen in APPE4 animals and the strongest effect on CCA incidence seen in $\mathrm{APP} / \varepsilon 2$ mice. We also found a profound effect of $A P O E$ genotype on $A \beta$ immunization related microhemorrhages. Surprisingly not the $\varepsilon 4$ allele but the $\varepsilon 2$ allele was associated with the greatest increase in the number of perivascular hemosiderin deposits. $10 \mathrm{D} 5 \mathrm{mAb}$ treated $\mathrm{APP} / \varepsilon 2$ mice had the highest increase in the number of all perivascular hemosiderin deposits and also in the number of deposits in small and large $(\geq 15 \mu \mathrm{m}$ in diameter) subcategories. The increase in the total number of hemosiderin deposits in $\mathrm{APP} / \varepsilon 2$ mice was approximately two-fold higher than these in $\mathrm{APP} / \varepsilon 3$ and $\mathrm{APP} / \varepsilon 4$ mice. $\mathrm{APP} / \varepsilon 2$ mice represented the only $A P O E$ genotype where $10 \mathrm{D} 5 \mathrm{mAb}$ immunization increased incidence of large hemosiderin deposits, bringing their number to three-fold value of the control group. Several human autopsy studies have shown that the $\varepsilon 2$ allele is an exacerbating factor of microhemorrhages among subjects with VA $\beta$ pathology and that this effect is linked to fibrinoid necrosis of vascular wall specifically associated with the $\varepsilon 2$ allele [55-57]. As mentioned above APP/ع2 mice also develop hypercholesterolemia and atherosclerosis, hence increased susceptibility to cerebral microhemorrhages and in particular high incidence of large hemosiderin deposits in $\mathrm{APP} / \varepsilon 2$ mice associated with immunotherapy can be a resultant of prevalent VA $\beta$ pathology, anti-A $\beta$ mAb effect, and cerebrovascular risk factors all cooperatively compromising vascular wall integrity. In contrast, $10 \mathrm{D} 5 \mathrm{mAb}$ treated $\mathrm{APP} / \varepsilon 3$ and $\mathrm{APP} / \varepsilon 4$ mice showed only an increase in the number of small hemosiderin deposits. Again the post-10D5 treatment number of hemosiderin deposits in $\mathrm{APP} / \varepsilon 3$ mice was the lowest among all $A P O E$ genotypes, indicating a relative vasculoprotective effect of the $\varepsilon 3$ allele, which has not been previously 
described in AD patients or APP Tg mice expressing human APOE alleles.

Exacerbation of VA $\beta$ associated microhemorrhages appears to be associated with propensity of anti-A $\mathrm{A}$ mAb to bind deposited $A \beta$. Thus, application of $\mathrm{N}$-terminus specific mAbs, which like10D5 binds epitopes exposed in $A \beta$ parenchymal plaques and VA $\beta$, but not mAbs, which like $\mathrm{m} 266$ bind the $A \beta$ central domain and do not bind to deposited $A \beta$ effect increased hemorrhage incidence $[64,65]$. However mAbs binding deposited $A \beta$ are generally more effective in clearing VA $\beta$ [12]. Time course analysis of VA $\beta$ related events during immunotherapy in PDAPP mice, revealed that a time window for increased incidence of microhemorrhages can last up to six months, but then their incidence diminishes drastically, which correlates with achieving significant clearance of both CAA and CCA [21]. Thus, the risk of brain microhemorrhages related to $A \beta$ immunotherapy may be a transient complication and possibly reduced in individuals with modest VA $\beta$ burden, who also have lower prevalence of spontaneous microbleeds $[58,59]$.

\section{Conclusions}

Utilizing $A P O E$ humanized $\mathrm{APP}_{\mathrm{SWE}} / \mathrm{PS} 1_{\mathrm{dE} 9}$ mice we demonstrated that $A P O E$ alleles differentially modulate various aspects of response to anti-A $\beta$ immunotherapy including $A \beta$ load reduction, microglia response, and incidence of cerebral microhemorrhages. This information can be utilized in design of clinical trials of anti-A $\beta$ mAbs and other $A \beta$ targeting therapeutics in order to maximize potency of studied approaches and minimize adverse reaction to the treatment.

\section{Additional files}

Additional file 1: Figure S1. Comparative analysis of $A \beta$ plaque load immunostained against $\mathrm{N}$-terminal and central $A \beta$ epitopes revealed no significant differences. a Representative microphotographs of coronal brain sections through the somatosensory cortex from the same TY11-15 control, and 10D5 mAb treated mice of APP/ع4 background, which were immunostained using HJ3.4 mAb directed against the N-terminus of $A \beta$ and $4 \mathrm{G} 8 \mathrm{mAb}$ directed against the mid-portion of $\mathrm{A} \beta$. $\mathbf{b}$ Unbiased analysis of the parenchymal $A B$ plaque load in the brain cortex revealed by HJ3.4 and 4G8 immunostaining. Values represent mean \pm SEM from 10 to 12 animals per group. $\mathbf{b} p<0.0001$ (one-way analysis of variance); ${ }^{* * *} p<0.0001$, TY11-15 control vs. 10D5 mAb treatment for matching anti-A $\beta$ immunostains (Sidak's post hoc test). Differences between HJ3.4 and 4G8 immunostaining in TY11-15 control and 10D5 mAb treatment groups were non-significant; not shown on the graph. Scale bar $50 \mu \mathrm{m}$ (a). (PDF $423 \mathrm{~kb}$ )

Additional file 2: Figure S2. Regional analysis of perivascular hemosiderin deposits identifies the brain cortex in mice of all APOE genotypes and the thalamus in APP/ع2 mice as brain structures susceptible to microbleeds associated with anti-A $\beta$ immunization. Shown are means ( \pm SEM) for counts of all brain perivascular hemosiderin deposits in the brain cortex, the hippocampus, the basal ganglia, the corpus callosum, the thalamus, the septum and the midbrain in APP/ع2 (a), APP/\&3 (b), and APP/ع4 mice (c) ( $n=5-11 /$ group). Perivascular hemosiderin deposits were counted on every tenth brain coronal cross-section along the entire rostro-caudal axis of the brain. a through (c) $p<$ 0.0001 (one-way analysis of variance); ${ }^{*} p<0.05,{ }^{* * *} p<0.001$, and ${ }^{* * * *} p<$ 0.0001 , TY11-15 control vs. 10D5 mAb treatment for matching brain structures and APOE genotypes (Sidak's post hoc test). For brain structures where the differences between TY11-15 control and 10D5 mAb treatment groups were not statistically significant $p$ values are not shown. Differences between Age control and TY11-15 groups were

non-significant for all structures (Sidak's post hoc test); $p$ values not shown on the graph. (PDF $419 \mathrm{~kb}$ )

\section{Abbreviations}

AD: Alzheimer's disease; APOE: human apolipoprotein E gene; Apoe: murine apolipoprotein E gene; apoE: apolipoprotein E; APP: APP $P_{S w / P S} 1_{\mathrm{dEg}}$ transgene; ARIA: amyloid related imaging abnormalities; $A \beta$ : $\beta$-amyloid; BBB: bloodbrain barrier; CAA: cerebral amyloid angiopathy; CCA: cerebral capillary $A \beta$; DAB: 3,3'-diaminobenzidine; FA: formic acid; $h$ : hippocampus; mAb: monoclonal antibody; PBS: phosphate buffered saline; PET: positron emission tomography; SEM: standard error of the mean; t: thalamus; Tg: transgenic; Th-S: Thioflavine-S; VA : vascular A $\beta$

\section{Acknowledgements}

We thank Dr. Frederique Bard of Janssen Alzheimer Immunotherapy for her advice in study design.

\section{Funding}

This work was supported by the following awards: NIA R01 AG047644 (DMH), NIA R01 AG031221 (MJS), NIA R01 AG053990 (MJS) and by Janssen Alzheimer Immunotherapy Sponsored Research Agreement No. 379851 (MJS).

\section{Availability of data and materials}

All data generated or analyzed during this study are included in this manuscript and its Additional files 1, and 2. The datasets used and/or analyzed during the current study available from the corresponding author on reasonable request.

\section{Authors' contributions}

JEP carried out morphometric analyses of A $\beta$ deposits, microglia, and hemosiderin deposits, and contributed to data analysis and manuscript preparation. JBB and SS performed husbandry and genotyping of APOE humanized APP SW $_{\text {PS1 }}$ dE9 mice and their treatment with 10D5 and TY11-15 antibodies. JLC carried out histological and immunohistochemical procedures. JK, PMS, and DMH developed APOE humanized APP $\mathrm{SW}_{\mathrm{SW}} / \mathrm{PS}_{\mathrm{dEg}}$ mice and contributed to manuscript preparation. MJS analyzed the data and wrote the manuscript. All authors have read and approved the final version of the manuscript.

\section{Competing interests}

This study was supported in part by Janssen Alzheimer Immunotherapy, which owns 10D5 mAb. Financial and in kind support (donation of 10D5 and TY11-15 mAbs) was provided under Sponsored Research Agreement No. 379851 to NYU (PI: MJ Sadowski).

\section{Consent for publication}

All authors agree to publication of this study.

\section{Ethical approval and consent to participate}

All mouse care and experimental procedures were approved by Institutional Animal Care and Use Committees of the New York University School of Medicine and the Washington University School of Medicine.

\section{Author details}

'Department of Neurology, New York University School of Medicine, New York, NY 10016, USA. ²Department of Biochemistry and Molecular Pharmacology, New York University School of Medicine, New York, NY 10016, USA. ${ }^{3}$ Department of Psychiatry, New York University School of Medicine, New York, NY 10016, USA. ${ }^{4}$ Department of Neurology, Washington University School of Medicine, St. Louis, MO 63110, USA. ${ }^{5}$ Knight Alzheimer's Disease Research Center, Washington University School of Medicine, St. Louis, MO 63110, USA. ${ }^{6}$ Hope Center for Neurological Disorders, Washington University School of Medicine, St. Louis, MO 63110, USA. ${ }^{7}$ Department of Neuroscience, Mayo Clinic College of Medicine, Jacksonville, FL 32224, USA. ${ }^{8}$ Department of Medicine (Geriatrics), Duke University School of Medicine, Durham, NC 27710, USA. ${ }^{9}$ Durham VA Medical Center's Geriatric Research, Education, and Clinical Center, Durham, NC 27710, USA. 
Received: 30 August 2016 Accepted: 24 January 2017 Published online: 31 January 2017

\section{References}

1. Selkoe DJ. SnapShot: pathobiology of Alzheimer's disease. Cell. 2013;154:468.

2. Selkoe DJ. Resolving controversies on the path to Alzheimer's therapeutics. Nat Med. 2011;17:1060-65.

3. Querfurth HW, LaFerla FM. Alzheimer's disease. N Engl J Med. 2010;362:329-44.

4. Liu CC, Kanekiyo T, Xu H, Bu G. Apolipoprotein E and Alzheimer disease: risk, mechanisms and therapy. Nat Rev Neurol. 2013;9:106-18.

5. Salloway S, Sperling R, Fox NC, Blennow K, Klunk W, Raskind M Sabbagh M, Honig LS, Porsteinsson AP, Ferris $S$, Reichert M, Ketter N, Nejadnik B, Guenzler V, Miloslavsky M, Wang D, Lu Y, Lull J, Tudor IC, Liu E, Grundman M, Yuen E, Black R, Brashear HR. Two phase 3 trials of bapineuzumab in mild-to-moderate Alzheimer's disease. N Engl J Med. 2014;370:322-33.

6. Ostrowitzki S, Deptula D, Thurfjell L, Barkhof F, Bohrmann B, Brooks DJ, Klunk WE, Ashford E, Yoo K, Xu ZX, Loetscher H, Santarelli L. Mechanism of amyloid removal in patients with Alzheimer disease treated with gantenerumab. Arch Neurol. 2012;69:198-207.

7. Rinne JO, Brooks DJ, Rossor MN, Fox NC, Bullock R, Klunk WE, Mathis CA Blennow K, Barakos J, Okello AA, de LS RM, Liu E, Koller M, Gregg KM, Schenk D, Black R, Grundman M. 11C-PiB PET assessment of change in fibrillar amyloid-beta load in patients with Alzheimer's disease treated with bapineuzumab: a phase 2, double-blind, placebo-controlled, ascending-dose study. Lancet Neurol. 2010;9:363-72.

8. Sevigny J, Chiao P, Bussiere T, Weinreb PH, Williams L, Maier M, Dunstan R, Salloway S, Chen T, Ling Y, O'Gorman J, Qian F, Arastu M, Li M, Chollate S, Brennan MS, Quintero-Monzon O, Scannevin RH, Arnold HM, Engber T, Rhodes K, Ferrero J, Hang Y, Mikulskis A, Grimm J, Hock C, Nitsch RM, Sandrock $A$. The antibody aducanumab reduces Abeta plaques in Alzheimer's disease. Nature. 2016;537:50-6.

9. Bard F, Cannon C, Barbour R, Burke RL, Games D, Grajeda H, Guido T, Hu K, Huang J, Johnson-Wood K, Khan K, Kholodenko D, Lee M, Lieberburg I, Motter R, Nguyen M, Soriano F, Vasquez N, Weiss K, Welch B, Seubert P, Schenk D, Yednock T. Peripherally administered antibodies against amyloid beta-peptide enter the central nervous system and reduce pathology in a mouse model of alzheimer disease [In Process Citation]. Nat Med. 2000;6:916-19.

10. Bard F, Barbour R, Cannon C, Carretto R, Fox M, Games D, Guido T, Hoenow K, Hu K, Johnson-Wood K, Khan K, Kholodenko D, Lee C, Lee M, Motter R, Nguyen M, Reed A, Schenk D, Tang P, Vasquez N, Seubert P, Yednock T. Epitope and isotype specificities of antibodies to beta -amyloid peptide for protection against Alzheimer's disease-like neuropathology. Proc Natl Acad Sci U S A. 2003;100:2023-28.

11. Seubert P, Barbour R, Khan K, Motter R, Tang P, Kholodenko D, Kling K, Schenk D, Johnson-Wood K, Schroeter S, Gill D, Jacobsen JS, Pangalos M, Basi G, Games D. Antibody capture of soluble Abeta does not reduce cortical Abeta amyloidosis in the PDAPP mouse. Neurodegener Dis. 2008:5:65-71.

12. Schroeter S, Khan K, Barbour R, Doan M, Chen M, Guido T, Gill D, Basi G, Schenk D, Seubert P, Games D. Immunotherapy reduces vascular amyloidbeta in PDAPP mice. J Neurosci. 2008;28:6787-93.

13. Sperling RA, Jack Jr CR, Black SE, Frosch MP, Greenberg SM, Hyman BT, Scheltens P, Carrillo MC, Thies W, Bednar MM, Black RS, Brashear HR, Grundman M, Siemers ER, Feldman HH, Schindler RJ. Amyloid-related imaging abnormalities in amyloid-modifying therapeutic trials: recommendations from the Alzheimer's Association Research Roundtable Workgroup. Alzheimers Dement. 2011;7:367-85.

14. Sperling R, Salloway S, Brooks DJ, Tampieri D, Barakos J, Fox NC, Raskind M, Sabbagh M, Honig LS, Porsteinsson AP, Lieberburg I, Arrighi HM, Morris KA, Lu Y, Liu E, Gregg KM, Brashear HR, Kinney GG, Black R, Grundman M. Amyloidrelated imaging abnormalities in patients with Alzheimer's disease treated with bapineuzumab: a retrospective analysis. Lancet Neurol. 2012;11:241-49.

15. Salloway S, Sperling R, Gilman S, Fox NC, Blennow K, Raskind M, Sabbagh M, Honig LS, Doody R, Van Dyck CH, Mulnard R, Barakos J, Gregg KM, Liu E, Lieberburg I, Schenk D, Black R, Grundman M. A phase 2 multiple ascending dose trial of bapineuzumab in mild to moderate Alzheimer disease. Neurol. 2009:73:2061-70.

16. Sullivan PM, Mezdour H, Quarfordt SH, Maeda N. Type III hyperlipoproteinemia and spontaneous atherosclerosis in mice resulting from gene replacement of mouse Apoe with human Apoe*2. J Clin Invest. 1998;102:130-35.

17. Sullivan PM, Mezdour H, Aratani Y, Knouff C, Najib J, Reddick RL, Quarfordt $\mathrm{SH}$, Maeda N. Targeted replacement of the mouse apolipoprotein E gene with the common human APOE3 allele enhances diet-induced hypercholesterolemia and atherosclerosis. J Biol Chem. 1997;272:17972-80.

18. Schmechel DE, Saunders AM, Strittmatter WJ, Crain BJ, Hulette CM, Joo SH, Pericak-Vance MA, Goldgaber D, Roses AD. Increased amyloid beta-peptide deposition in cerebral cortex as a consequence of apolipoprotein E genotype in late-onset Alzheimer disease. Proc Natl Acad Sci U S A. 1993;90:9649-53.

19. Pankiewicz JE, Guridi M, Kim J, Asuni AA, Sanchez S, Sullivan PM, Holtzman DM, Sadowski MJ. Blocking the apoE/A-beta interaction ameliorates A-betarelated pathology in APOE epsilon 2 and epsilon 4 targeted replacement Alzheimer model mice. Acta Neuropathol Commun. 2014;2:75.

20. Kuszczyk MA, Sanchez S, Pankiewicz J, Kim J, Duszczyk M, Guridi M, Asuni AA, Sullivan PM, Holtzman DM, Sadowski MJ. Blocking the Interaction between Apolipoprotein E and Abeta Reduces Intraneuronal Accumulation of Abeta and Inhibits Synaptic Degeneration. Am J Pathol. 2013;182:1750-68.

21. Zago W, Schroeter $S$, Guido T, Khan K, Seubert P, Yednock T, Schenk D, Gregg KM, Games D, Bard F, Kinney GG. Vascular alterations in PDAPP mice after anti-Abeta immunotherapy: Implications for amyloid-related imaging abnormalities. Alzheimers Dement. 2013;9:S105-15.

22. Hartman RE, Izumi Y, Bales KR, Paul SM, Wozniak DF, Holtzman DM. Treatment with an amyloid-beta antibody ameliorates plaque load, learning deficits, and hippocampal long-term potentiation in a mouse model of Alzheimer's disease. J Neurosci. 2005;25:6213-20.

23. Asuni AA, Guridi M, Pankiewicz JE, Sanchez S, Sadowski MJ. Modulation of amyloid precursor protein expression reduces beta-amyloid deposition in a mouse model. Ann Neurol. 2014:75:684-99.

24. Sadowski MJ, Pankiewicz J, Scholtzova H, Mehta PD, Prelli F, Quartermain D, Wisniewski T. Blocking the apolipoprotein E/amyloid-beta interaction as a potential therapeutic approach for Alzheimer's disease. Proc Natl Acad Sci U S A. 2006;103:18787-92.

25. Fryer JD, Taylor JW, DeMattos RB, Bales KR, Paul SM, Parsadanian M, Holtzman DM. Apolipoprotein E markedly facilitates age-dependent cerebral amyloid angiopathy and spontaneous hemorrhage in amyloid precursor protein Transgenic mice. J Neurosci. 2003;23:7889-96.

26. Pfeifer M, Boncristiano S, Bondolfi L, Stalder A, Deller T, Staufenbiel M, Mathews PM, Jucker M. Cerebral hemorrhage after passive anti-A beta immunotherapy. Science. 2002;298:1379.

27. Wisniewski HM, Sadowski M, Jakubowska-Sadowska K, Tarnawski M, Wegiel J. Diffuse, lake-like amyloid-beta deposits in the parvopyramidal layer of the presubiculum in Alzheimer disease. J Neuropath Exp Neurol. 1998;57:674-83.

28. Cortes-Sol A, Lara-Garcia M, Alvarado M, Hudson R, Berbel P, Pacheco P. Inner capillary diameter of hypothalamic paraventricular nucleus of female rat increases during lactation. BMC Neurosci. 2013;14:7.

29. Thal DR, Capetillo-Zarate E, Larionov S, Staufenbiel M, Zurbruegg S, Beckmann N. Capillary cerebral amyloid angiopathy is associated with vessel occlusion and cerebral blood flow disturbances. Neurobiol Aging. 2009;30:1936-48.

30. Ito D, Imai Y, Ohsawa K, Nakajima K, Fukuuchi Y, Kohsaka S. Microgliaspecific localisation of a novel calcium binding protein, Iba1. Brain Res Mol Brain Res. 1998;57:1-9.

31. Zotova E, Bharambe V, Cheaveau M, Morgan W, Holmes C, Harris S, Neal JW, Love S, Nicoll JA, Boche D. Inflammatory components in human Alzheimer's disease and after active amyloid-beta42 immunization. Brain. 2013;136:2677-96.

32. Castellano JM, Kim J, Stewart FR, Jiang H, DeMattos RB, Patterson BW, Fagan AM, Morris JC, Mawuenyega KG, Cruchaga C, Goate AM, Bales KR, Paul SM, Bateman RJ, Holtzman DM. Human apoE Isoforms Differentially Regulate Brain Amyloid-ß Peptide Clearance. Sci Transl Med. 2011;3:89ra57.

33. Yu JT, Tan L, Hardy J. Apolipoprotein E in Alzheimer's disease: an update. Annu Rev Neurosci. 2014;37:79-100.

34. Hohsfield LA, Humpel C. Migration of blood cells to beta-amyloid plaques in Alzheimer's disease. Exp Gerontol. 2015;65:8-15.

35. Chakrabarty P, Li A, Ceballos-Diaz C, Eddy JA, Funk CC, Moore B, DiNunno N, Rosario AM, Cruz PE, Verbeeck C, Sacino A, Nix S, Janus C, Price ND, Das P, Golde TE. IL-10 alters immunoproteostasis in APP mice, increasing plaque burden and worsening cognitive behavior. Neuron. 2015;85:519-33.

36. Bales KR, Liu F, Wu S, Lin S, Koger D, DeLong C, Hansen JC, Sullivan PM, Paul SM. Human APOE isoform-dependent effects on brain beta-amyloid levels in PDAPP transgenic mice. J Neurosci. 2009;29:6771-79.

37. Chakrabarty P, Tianbai L, Herring A, Ceballos-Diaz C, Das P, Golde TE. Hippocampal expression of murine IL-4 results in exacerbation of amyloid deposition. Mol Neurodegener. 2012;7:36. 
38. D'Andrea MR, Cole GM, Ard MD. The microglial phagocytic role with specific plaque types in the Alzheimer disease brain. Neurobiol Aging. 2004; 25:675-83.

39. Morgan D. The role of microglia in antibody-mediated clearance of amyloid-beta from the brain. CNS Neurol Disord Drug Targets. 2009:8:7-15.

40. Thal DR, Ghebremedhin E, Rub U, Yamaguchi H, Del Tredici K, Braak H. Two types of sporadic cerebral amyloid angiopathy. J Neuropath Exp Neurol. 2002;61:282-93.

41. Thal DR, Ghebremedhin E, Orantes M, Wiestler OD. Vascular pathology in Alzheimer disease: correlation of cerebral amyloid angiopathy and arteriosclerosis/lipohyalinosis with cognitive decline. J Neuropathol Exp Neurol. 2003;62:1287-301.

42. Thal DR, Griffin WS, de Vos RA, Ghebremedhin E. Cerebral amyloid angiopathy and its relationship to Alzheimer's disease. Acta Neuropathol. 2008:115:599-609.

43. Thal DR, Papassotiropoulos A, Saido TC, Griffin WS, Mrak RE, Kolsch H, Del TK, Attems J, Ghebremedhin E. Capillary cerebral amyloid angiopathy identifies a distinct APOE epsilon4-associated subtype of sporadic Alzheimer's disease. Acta Neuropathol. 2010;120:169-83.

44. Fryer JD, Simmons K, Parsadanian M, Bales KR, Paul SM, Sullivan PM, Holtzman DM. Human apolipoprotein E4 alters the amyloid-beta 40: 42 ratio and promotes the formation of cerebral amyloid angiopathy in an amyloid precursor protein transgenic model. J Neurosci. 2005:25:2803-10.

45. Chalmers K, Wilcock GK, Love S. APOE epsilon 4 influences the pathological phenotype of Alzheimer's disease by favouring cerebrovascular over parenchymal accumulation of A beta protein. Neuropathol Appl Neurobiol. 2003;29:231-38

46. Trembath D, Ervin JF, Broom L, Szymanski M, Welsh-Bohmer K, Pieper C, Hulette CM. The distribution of cerebrovascular amyloid in Alzheimer's disease varies with ApoE genotype. Acta Neuropathol. 2007;113:23-31.

47. Wisniewski T, Castaño EM, Golabek AA, Vogel T, Frangione B. Acceleration of Alzheimer's fibril formation by apolipoprotein E in vitro. Am J Pathol. 1994; 145:1030-35.

48. Deane R, Sagare A, Hamm K, Parisi M, Lane S, Finn MB, Holtzman DM Zlokovic BV. apoE isoform-specific disruption of amyloid beta peptide clearance from mouse brain. J Clin Invest. 2008;118:4002-13.

49. Merlini M, Meyer EP, Ulmann-Schuler A, Nitsch RM. Vascular beta-amyloid and early astrocyte alterations impair cerebrovascular function and cerebral metabolism in transgenic arcAbeta mice. Acta Neuropathol. 2011;122:293-311.

50. Klohs J, Baltes C, Princz-Kranz F, Ratering D, Nitsch RM, Knuesel I, Rudin M. Contrast-enhanced magnetic resonance microangiography reveals remodeling of the cerebral microvasculature in transgenic ArcAbeta mice. J Neurosci. 2012;32:1705-13.

51. Poels MM, Vernooij MW, Ikram MA, Hofman A, Krestin GP, van der Lugt A, Breteler MM. Prevalence and risk factors of cerebral microbleeds: an update of the Rotterdam scan study. Stroke. 2010;41:S103-6.

52. Vernooij MW, van der Lugt A, Ikram MA, Wielopolski PA, Niessen WJ, Hofman A, Krestin GP, Breteler MM. Prevalence and risk factors of cerebral microbleeds: the Rotterdam Scan Study. Neurol. 2008;70:1208-14.

53. Kovari E, Charidimou A, Herrmann FR, Giannakopoulos P, Bouras C, Gold G. No neuropathological evidence for a direct topographical relation between microbleeds and cerebral amyloid angiopathy. Acta Neuropathol Commun. 2015;3:49.

54. Kim M, Bae HJ, Lee J, Kang L, Lee S, Kim S, Lee JE, Lee KM, Yoon BW, Kwon O, Koo JS, Kim BK. APOE epsilon2/epsilon4 polymorphism and cerebral microbleeds on gradient-echo MRI. Neurol. 2005:65:1474-75.

55. McCarron MO, Nicoll JAR, Ironside JW, Love S, Alberts MJ, Bone I. Cerebral amyloid angiopathy-related hemorrhage interaction of APOE epsilon 2 with putative clinical risk factors. Stroke. 1999;30:1643-46.

56. McCarron MO, Nicoll JAR, Stewart J, Ironside JW, Mann DMA, Love S, Graham DI, Dewar D. The apolipoprotein E epsilon 2 allele and the pathological features in cerebral amyloid angiopathy-related hemorrhage. J Neuropath Exp Neurol. 1999:58:711-18.

57. McCarron MO, Nicoll JAR. High frequency of apolipoprotein E epsilon 2 allele is specific for patients with cerebral amyloid angiopathy-related haemorrhage. Neurosci Lett. 1998;247:45-8.

58. Yates PA, Desmond PM, Phal PM, Steward C, Szoeke C, Salvado O, Ellis KA, Martins RN, Masters CL, Ames D, Villemagne VL, Rowe CC. Incidence of cerebral microbleeds in preclinical Alzheimer disease. Neurol. 2014;82:1266-73.

59. Yates $P A$, Sirisriro $R$, Villemagne $V L$, Farquharson $S$, Masters $C L$, Rowe $C C$. Cerebral microhemorrhage and brain beta-amyloid in aging and Alzheimer disease. Neurol. 2011;77:48-54.
60. Song TJ, Kim J, Lee HS, Nam CM, Nam HS, Kim YD, Heo JH. Distribution of cerebral microbleeds determines their association with impaired kidney function. J Clin Neurol. 2014;10:222-28.

61. Song TJ, Kim J, Kim YD, Nam HS, Lee HS, Nam CM, Heo JH. The distribution of cerebral microbleeds determines their association with arterial stiffness in non-cardioembolic acute stroke patients. Eur J Neurol. 2014;21:463-69.

62. Mahley RW, Rall Jr SC. Apolipoprotein E: far more than a lipid transport protein. Annu Rev Genomics Hum Genet. 2000;1:507-37.

63. Bales KR, O'Neill SM, Pozdnyakov N, Pan F, Caouette D, Pi Y, Wood KM, Volfson D, Cirrito JR, Han BH, Johnson AW, Zipfel GJ, Samad TA. Passive immunotherapy targeting amyloid-beta reduces cerebral amyloid angiopathy and improves vascular reactivity. Brain. 2016;139:563-77.

64. Racke MM, Boone LI, Hepburn DL, Parsadainian M, Bryan MT, Ness DK Piroozi KS, Jordan WH, Brown DD, Hoffman WP, Holtzman DM, Bales KR, Gitter BD, May PC, Paul SM, DeMattos RB. Exacerbation of cerebral amyloid angiopathy-associated microhemorrhage in amyloid precursor protein transgenic mice by immunotherapy is dependent on antibody recognition of deposited forms of amyloid beta. J Neurosci. 2005;25:629-36.

65. Thakker DR, Weatherspoon MR, Harrison J, Keene TE, Lane DS, Kaemmerer WF, Stewart GR, Shafer LL. Intracerebroventricular amyloid-beta antibodies reduce cerebral amyloid angiopathy and associated micro-hemorrhages in aged Tg2576 mice. Proc Natl Acad Sci U S A. 2009:106:4501-06.

\section{Submit your next manuscript to BioMed Central and we will help you at every step:}

- We accept pre-submission inquiries

- Our selector tool helps you to find the most relevant journal

- We provide round the clock customer support

- Convenient online submission

- Thorough peer review

- Inclusion in PubMed and all major indexing services

- Maximum visibility for your research

Submit your manuscript at www.biomedcentral.com/submit
) Biomed Central 